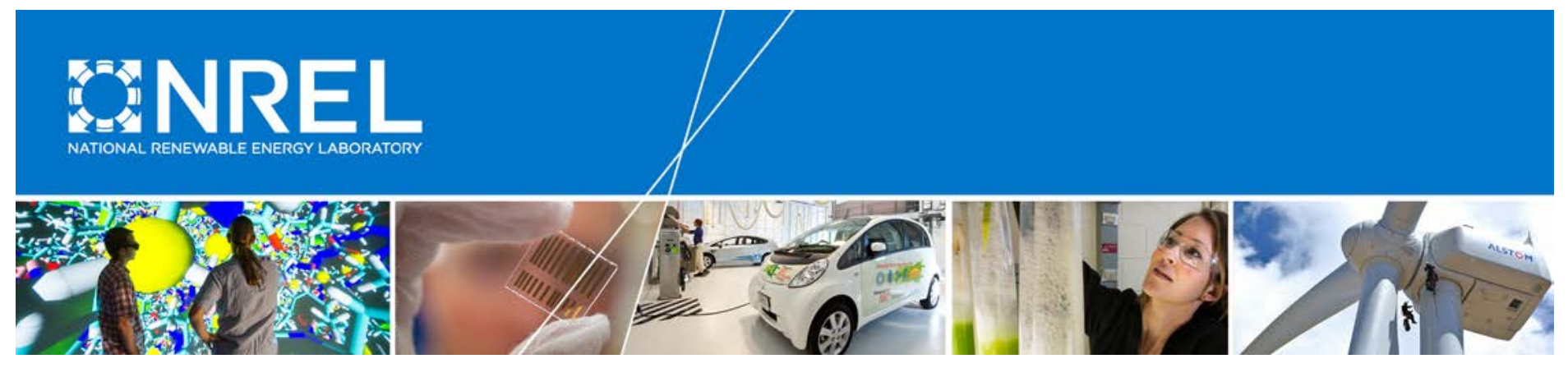

\title{
Photovoltaic Shading Testbed for Module-Level Power Electronics: 2016 Performance Data Update
}

Chris Deline National Renewable Energy Laboratory

Jenya Meydbray and Matt Donovan PV Evolution Labs / DNV GL

NREL is a national laboratory of the U.S. Department of Energy Office of Energy Efficiency \& Renewable Energy Operated by the Alliance for Sustainable Energy, LLC

This report is available at no cost from the National Renewable Energy Laboratory (NREL) at www.nrel.gov/publications.

Technical Report

NREL/TP- 5J00-62471

September 2016

Contract No. DE-AC36-08G028308 


\section{Photovoltaic Shading Testbed for Module-Level Power Electronics: 2016 Performance Data Update}

Chris Deline National Renewable Energy Laboratory

Jenya Meydbray and Matt Donovan PV Evolution Labs / DNV GL

Prepared under Task No. SS12.3050

NREL is a national laboratory of the U.S. Department of Energy Office of Energy Efficiency \& Renewable Energy Operated by the Alliance for Sustainable Energy, LLC

This report is available at no cost from the National Renewable Energy Laboratory (NREL) at www.nrel.gov/publications.

National Renewable Energy Laboratory 15013 Denver West Parkway Golden, CO 80401

303-275-3000 • www.nrel.gov
Technical Report

NREL/TP- 5J00-62471

September 2016

Contract No. DE-AC36-08G028308 


\section{NOTICE}

This report was prepared as an account of work sponsored by an agency of the United States government. Neither the United States government nor any agency thereof, nor any of their employees, makes any warranty, express or implied, or assumes any legal liability or responsibility for the accuracy, completeness, or usefulness of any information, apparatus, product, or process disclosed, or represents that its use would not infringe privately owned rights. Reference herein to any specific commercial product, process, or service by trade name, trademark, manufacturer, or otherwise does not necessarily constitute or imply its endorsement, recommendation, or favoring by the United States government or any agency thereof. The views and opinions of authors expressed herein do not necessarily state or reflect those of the United States government or any agency thereof.

This report is available at no cost from the National Renewable Energy Laboratory (NREL) at www.nrel.gov/publications.

Available electronically at SciTech Connect http:/www.osti.gov/scitech

Available for a processing fee to U.S. Department of Energy and its contractors, in paper, from:

U.S. Department of Energy

Office of Scientific and Technical Information

P.O. Box 62

Oak Ridge, TN 37831-0062

OSTI http://www.osti.gov

Phone: 865.576.8401

Fax: 865.576.5728

Email: reports@osti.gov

Available for sale to the public, in paper, from:

U.S. Department of Commerce

National Technical Information Service

5301 Shawnee Road

Alexandria, VA 22312

NTIS http://www.ntis.gov

Phone: 800.553 .6847 or 703.605 .6000

Fax: 703.605.6900

Email: orders@ntis.gov 


\section{Photovoltaic Shading Testbed for Module- Level Power Electronics: 2016 Performance Data Update}

\section{Abstract}

The 2012 NREL report, "Photovoltaic Shading Testbed for Module-Level Power Electronics," provides a standard methodology for estimating the performance benefit of distributed power electronics under partial shading conditions. Since the release of the report, experiments have been conducted for a number of products, under different weather conditions and for different system configurations. Drawing from these experiences, updates to the test and analysis methods are recommended. Proposed changes in data processing have the benefit of reducing the sensitivity to measurement errors and weather variability, as well as bringing the updated performance score more in line with measured and simulated values of the shade recovery benefit of distributed photovoltaic power electronics.

Also, due to the emergence of new technologies, including submodule embedded power electronics, the shading method has been extended to include power electronics that operate at a finer granularity than the module level. A minor update to the method is proposed to account for these emerging technologies that will respond to shading differently than module-level devices.

A revised version of the original test procedure is given here, along with updates for submodule electronics. The partial-shading test remains a repeatable test procedure that attempts to simulate shading situations as would be experienced by typical residential or commercial rooftop photovoltaic systems. Performance data for multiple products tested using this method are discussed, based on equipment from Enphase, Solar Edge, Maxim Integrated, and SMA. In general, the annual recovery of shading losses from the modulelevel electronics evaluated is $25 \%-35 \%$, with the major difference between different trials being related to the number of parallel strings in the test installation rather than differences between the equipment tested.

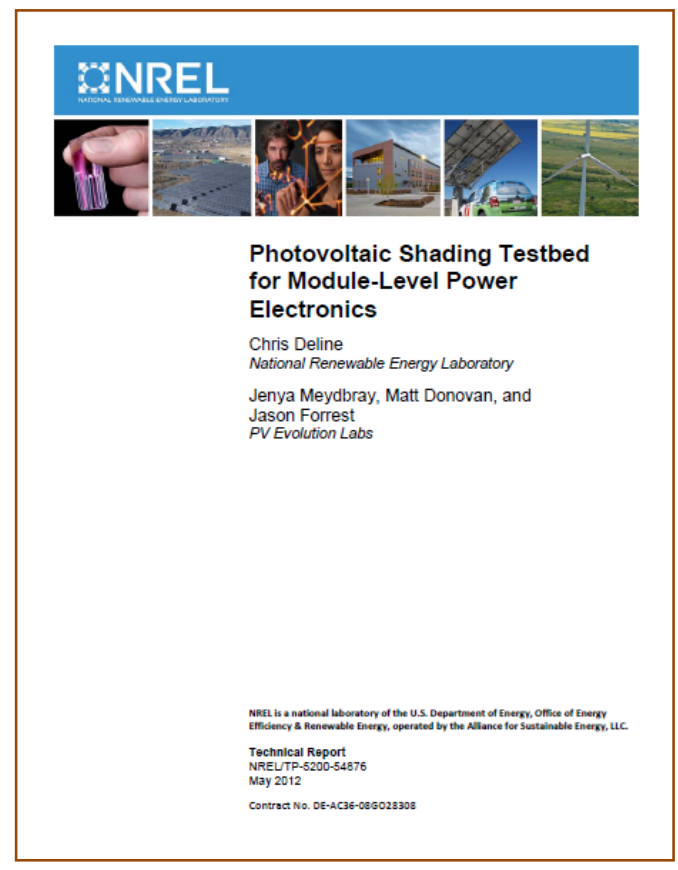

Figure 1. 2012 NREL report "Photovoltaic Shading Testbed for Module-Level Power Electronics." 


\section{Overview}

The 2012 NREL report, "Photovoltaic Shading Testbed for Module-Level Power Electronics" [1], provides the groundwork for experimental evaluation of distributed power electronics. It is a repeatable, experimental method that can be conducted over a short period of time $(<1$ week) for a variety of distributed photovoltaic (PV) power electronics such as microinverters and DC power optimizers. The test is designed such that variability in the weather and measurement uncertainty can be minimized, and short-term power production can be extrapolated to determine annual energy improvement under different shading conditions.

In the original proposed test, a series of partial-shading conditions were applied to two side-byside PV systems - one equipped with the device under test (DUT) and the other equipped with a standard string inverter (reference). The relative performance of one system versus the other was averaged using a weighted average based on survey data that was collected for representative rooftop installations. Three shade conditions were simulated by different weighting conditions: "light" shading ( $7 \%$ annual irradiance reduction), "moderate" shading (15\%-19\% irradiance reduction), and "heavy" shading ( $25 \%$ irradiance reduction). These shading conditions were to provide the basis for a weighted-average annual performance score, representing the percentage of increased annual production from the use of the device in that particular system configuration.

In the updated method considered here, the experimental methodology remains largely the same. A similar method of partial shading is proposed, using the same type of shading fabric and amounts of shade. In the case of submodule power electronics, a slight modification to the application of shade may be required to account for their particular response to partial shading. A major modification to the original method lies in the analysis of the measured shade data. The "table method" originally proposed in 2012 is entirely removed because it was found to be unreasonably sensitive to measurement errors, among other problems. The alternate "normalized method" was found to generate repeatable data because the shaded data are normalized by unshaded data on the same system. This removes bias errors from differences in STC rating between the two comparison systems, as well as removing variability not captured by temperature or irradiance throughout the day.

Additional improvements to the "normalized method" are proposed here resulting in a more accurate final shade-mitigation score. The shade-mitigation score is an estimate of the percentage of shading loss that is recovered by the use of the DUT on an annual basis. This value can be used directly in annual performance estimation software such as PVWatts or PVSyst to estimate the performance and economic benefit of distributed power electronics under different system configurations.

\section{Test Configuration: Overview and Rationale}

The partial-shading testbed was designed to recreate conditions of medium-sized residential rooftop systems, composed of 2-3 parallel strings of 10-12 panels. This was done for reasons explained in the original paper and supported by references $[2,3,4,5]$. A side-by-side test with 
two identical arrays is employed. The reference array is equipped with a typical string inverter, whereas the DUT array will be equipped with the DUT to be tested.

One consideration for the reference array is that its inverter should be chosen with a DC operating window to accept a low-voltage DC input. Uniform shading of up to $30 \%$ of the modules in a string should be tolerated before minimum maximum-power-point tracking (MPPT) tracking voltage limits are reached. See additional discussion on the reference inverter's DC input range in [1].

Measurement of array performance should be conducted using revenue-grade AC $\mathrm{kWh}$ meters with $0.2 \%$ accuracy (ANSI C12.20) and $1 \mathrm{Wh}$ resolution at the output of each array. If AC microinverters are used in the DUT array, the $\mathrm{kWh}$ meter should be placed at the point of common AC connection of all of the microinverters in the array. Performance comparison will be gauged by periodic measurement of $\mathrm{kWh}$ production of both installations taking 1-min average $\mathrm{AC} \mathrm{kWh}$ data.

Temperature should be collected at the back of a similarly located module in each string (e.g., top row edge, bottom row middle). Plane-of-array irradiance should be monitored using a silicon photodetector, thermopile pyranometer, or reference cell. Temperature and irradiance are used to translate field performance to a common reference condition (here, STC conditions are used: $1000 \mathrm{~W} / \mathrm{m}^{2}$ and $25^{\circ} \mathrm{C}$ module temperature).

\subsection{Direct-Shading Procedure}

Direct shading is applied to both the reference and DUT arrays using a semi-transparent mesh material in a series of different shade conditions (between 20 and 30 unique shading configurations, depending on the system under test). A discussion of the relative merits of direct vs. obstruction shading can be found in [1]. The opacity of the shading fabric being used should also be at least $50 \%$ with a uniform spectral response. The specific mesh suggested here is McMaster-Carr P/N 87655K134. This mesh has been found to have a transmittance of 36\% with good spectral uniformity.

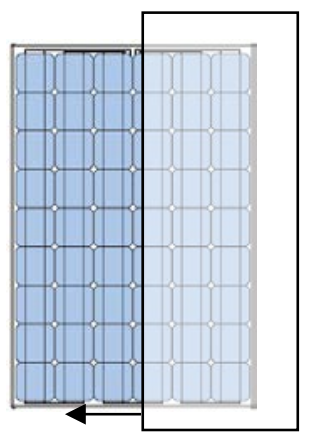

Figure 2. Partial shading of a single module should use $50 \%$ opacity filter to cover all of a given bypass diode submodule (one-third of the module for 60 -cell modules).
The exact methodology for shading the solar panels is as follows. A row of modules to be shaded are arranged in portrait configuration. This will allow side-to-side shading to cover one bypass-diode-protected submodule at a time. (In a typical 60-cell module, each one-third of the module is protected by a single bypass diode.) The shading screen is drawn from one side of the row to the other, in one-third module increments (Fig. 2). The shading material should be affixed to the frame of the module at the top and bottom to prevent the shade screen from moving during a test measurement period. (Clothespins work 
well!) With shade covering the entire submodule, performance is less dependent on individual cell reverse-bias characteristics, which can vary widely [6]. An argument can be made that shade in the real world does not conform to this approach of covering an entire submodule at a time. However, from an electrical standpoint, there is little difference between a single cell in a submodule being shaded, and the entire submodule being shaded. The method here assumes a limit condition--where any shade on a given submodule is equivalent to the entire submodule being shaded. Otherwise, there are an infinite number of permutations of shadow shape.

Prior to collecting shaded data on the two arrays, at least one full day of unshaded performance should be collected. This allows for the performance of each array under each shaded condition to be compared with unshaded performance at a similar time of day on a day immediately preceding the shaded data.

Shading is applied to each array according to Table 1. This table assumes three parallel strings of 12 modules and 3 bypass diodes per module for a total of 36 submodules in each string. The shading configuration is specified by the naming convention $A: B: C$ where $A$ is the number of submodules shaded in the first string, $B$ is the number of submodules shaded in the second, and $C$ is the number of submodules shaded in the third string. Three separate shade ratios are used, each shading a different proportion of the three parallel strings. With single-string shading, only one of the three strings is shaded, with the other two strings receiving zero shading. It is therefore denoted by the shade vector $n: 0: 0$ where $n$ is the number of shaded submodules in string $A$, up to a maximum of 36 . The two other shade vectors used in this procedure are twostring shading ( $n: n: 0)$ and three-string shading ( $n: n: n)$. As an example, the single-string shading case 4:0:0 has string $A$ with 4 submodules shaded (one full module plus one-third of the next module) and strings $B$ and $C$ with no shading. In another example, the uniform shading case 12:12:12 has all three parallel strings with four complete modules shaded (12 submodules).

Table 1. Shade Conditions for the Direct-Shading Test, Three Parallel Strings of 12 Modules Each
Single-string $(n: 0: 0)$ shading
Two-string ( $n: n: 0)$ shading
Three-string $(n: n: n)$ shading

\begin{tabular}{c|c|c|c|c|}
\hline \hline \multicolumn{2}{l|}{ Submodules shaded $n$ (of 36) } & \multicolumn{2}{l|}{ Submodules shaded $n$ (of 36) } & \multicolumn{2}{l|}{ Submodules shaded $n(/ 36)$} \\
\hline String 1 & String 2,3 & String 1,2 & String 3 & String 1,2,3 \\
\hline $1,4,8,12,16,20,24,28,32,35$ & 0 & $1,4,8,12,16,20,24,28,32,35$ & 0 & $1,4,8,12,16,20,24,28,32,35$
\end{tabular}

For each of the shading conditions considered, a minimum 5-min measurement interval is required, preceded by a settling time to enable the inverters to reach steady-state operation. The valid conditions for data collection include solar incidence angle less than 50 degrees with respect to the plane of array (POA), as well as clear-sky conditions and POA irradiance greater than $500 \mathrm{~W} / \mathrm{m}^{2}$.

A final consideration deals with inverter peak-power operation. For the reference inverter to properly track the global maximum power point, the reference inverter should not be started up in a partially shaded condition. If a particular heavily shaded condition is desired, that shading 


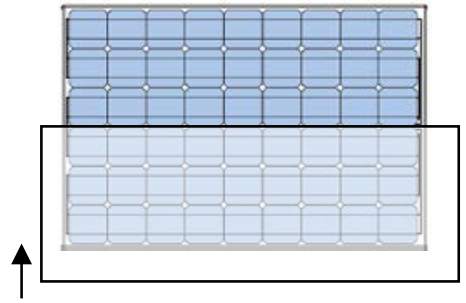

Figure 3. Shading for DUT designed for interrow shading should be applied across an entire row from the bottom of the module up. condition should be arrived at gradually, giving the inverter several minutes to adjust to each subsequent operating voltage.

Submodule-level DUT: The original shading procedure was developed for distributed power electronics acting at the module level. In the case of a DUT that is applied at a finer granularity (such as the bypass-diode level), a submodule should be defined as the smallest group of PV cells connected to a single power electronics converter, possibly down to a single

solar cell. In this case, the number of shaded submodules in Table 1 represents the fraction of the entire string that should be shaded.

For a DUT intended specifically for the mitigation of inter-row shading losses, direct shading should be applied consistent with the expected shading pattern. For example, the entire string should be shaded uniformly from the bottom of the panel up (Fig. 3). In this case, the submodule shading values of Table 1 should be converted into a fraction of each module to be shaded by dividing by 36. For instance, in the case of inter-row shading, the 12:12:0 shading condition involves shading the bottom third of each module in strings $A$ and $B$. A methodology for interrow shading comparison is detailed in Chapter 5.

\section{Analysis Methodology}

\subsection{Definition of Performance Metrics}

Partial-shading results focus on energy production normalized to STC, defined as operation at $1000 \mathrm{~W} / \mathrm{m}^{2}$ and $25^{\circ} \mathrm{C}$ cell temperature. For a given shade condition, an array's energy production can be normalized to this common reference condition with knowledge of the average POA irradiance, the module's temperature coefficient $\beta$, and back-of-module temperature during the measurement period:

$$
\text { STC Energy }=\text { Energy } \times\left(\frac{1000 \mathrm{~W} / \mathrm{m}^{2}}{\text { Irradiance }}\right) \times\left[1+\beta\left(T_{\text {module }}-25^{\circ} \mathrm{C}\right)\right]
$$

A second value is the amount of energy produced by the reference and DUT system relative to unshaded conditions. Here, Normalized Performance is used to express the energy production of a shaded system on a scale of zero to one, with the following definition:

$$
\text { Normalized Performance }=\frac{\text { Shaded STC energy }}{\text { Unshaded STC energy }}
$$


Normalized Performance represents the impact of shading on either the reference or DUT system for each particular shading configuration. Therefore, through the course of measurement, a separate normalized performance value is obtained for each reference or DUT system, at each unique shading point.

With this treatment of Normalized Performance, the amounts of shaded and unshaded energy generated at STC are obtained from the same time period on consecutive days (one day with shading applied, the other with no shading). In effect, we are comparing the shaded system against itself under very similar conditions with no shade. By using tests measured on consecutive days and at the same time periods during those days to compare shaded to unshaded performance, we obtain a measure of system shading impact that is less susceptible to errors caused by irradiance and temperature normalizations, angle of incidence, and spectrum, because all of those parameters are similar on both days.

Example Normalized Performance data: As an example of how the normalized performance data can be displayed for the various shading configurations, the experimental results previously published in [1] are shown as Normalized Performance in Fig. 4. The DUT array is equipped with Enphase M215 microinverters, compared to a reference array with a string inverter. It is clear that although the DUT array has a linear response with respect to shade extent, the Reference array has a nonlinear shade response with greater losses from shade.

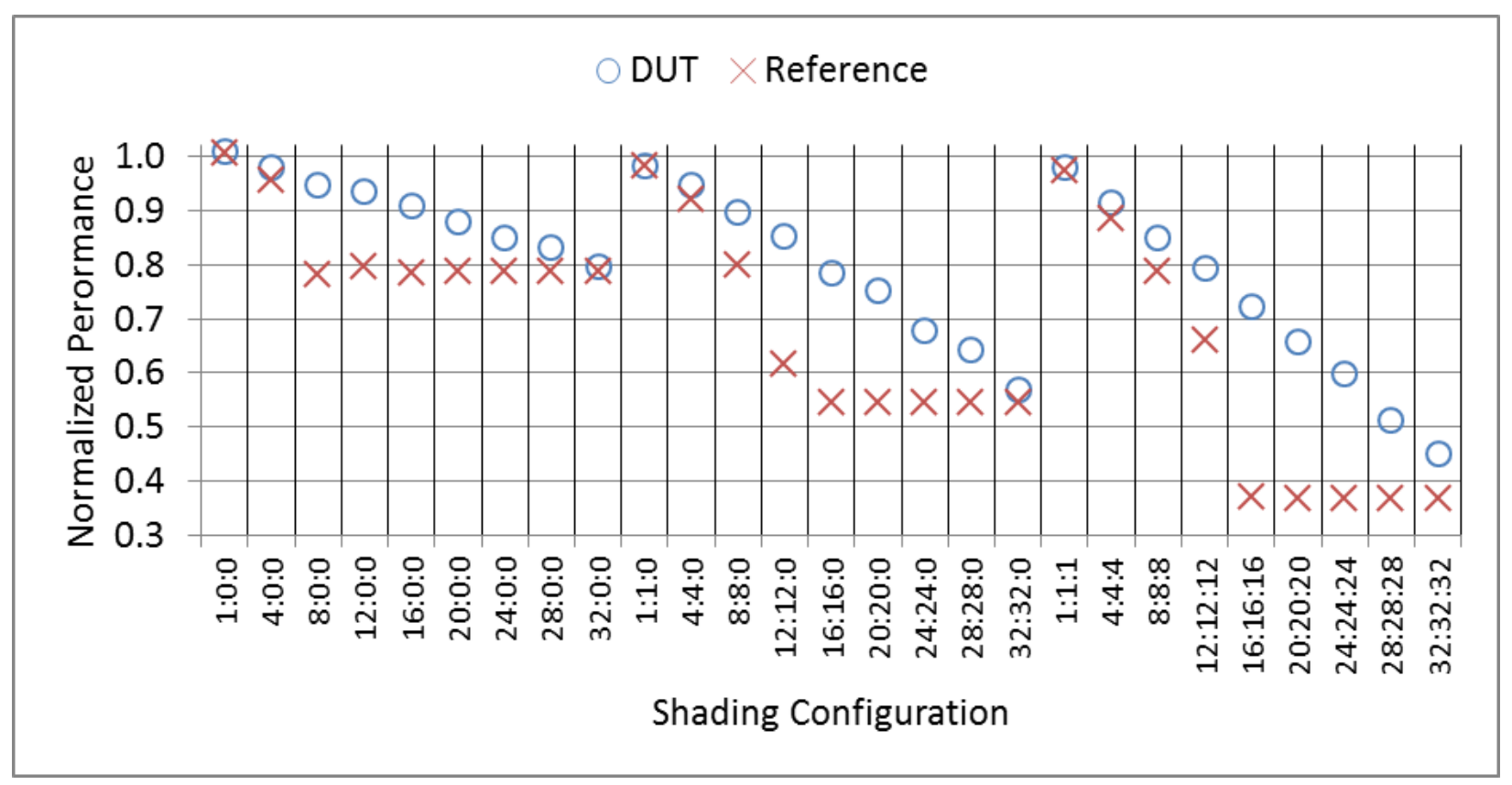

Figure 4. Normalized Performance data for the experimental results originally provided in Ref [1], Fig. 13.

\subsection{Shading Histograms from Residential Survey}

We now move on from synthetic shading on our test array to a discussion on how shading typically occurs in real-world residential installations. To be able to make some generalizations, 
site-survey information was obtained from 66 residential PV installations in California. In these measurements, a panoramic view of surrounding obstructions was taken, and the annual irradiance lost due to shade was calculated. Here, annual irradiance is defined as "Solar Access" measured by a Solmetric Suneye imaging tool [7]. This measurement is averaged across the installation using multiple images taken at the corners of the PV array. The annual irradiance loss for these various site surveys are shown in Fig. 5.

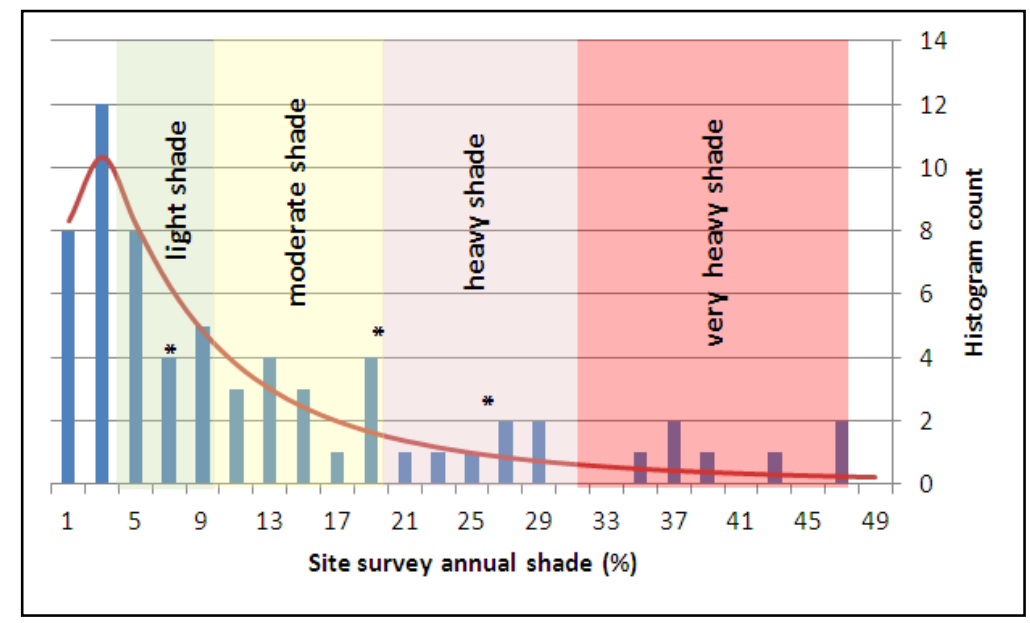

Figure 5. Site survey details for 66 residential installations. The three asterisks * indicate the three shade-weighting conditions targeted in this test.

Note that the annual irradiance losses shown above in Fig. 5 are not exactly the same as the expected electrical losses in the PV system. To determine the actual power losses from shading would require detailed simulations to be conducted for each system, or to have the shading obstructions removed for a period of time for a before-and-after comparison. Because this sort of validation is impractical, we are assuming here that a 1:1 relationship exists between a system's reduced Solar Access, and the annual power loss on that system due to shading.

Rather than analyzing each of the systems in our distribution, three representative systems are chosen with different amounts of shading. These three systems, marked in Fig. 5, represent light, medium, and heavy residential shading conditions, with annual Solar Access shading reductions of $7 \%, 19 \%$, and $26 \%$, respectively. Additional details about these three representative systems may be found in [1].

The next step is to investigate the distribution of shading in each system. A key question is whether the system's annual shading loss stems from of a small amount of shade occurring over a large period of time, or infrequent instances of heavy shading. A histogram is given in Fig. 6 that reflects the amount of time in a year that a system operates under different amounts of system shading (from unshaded to full system shading). The y-axis of the histogram is scaled by the incident irradiance (unshaded) during each associated time period. This method of weighting by irradiance accounts for the larger impact for shade occurring during high-irradiance conditions. It can be noted that even for the heavily shaded PV installation, the largest single component of the histogram is the $0 \%$ shaded condition. 


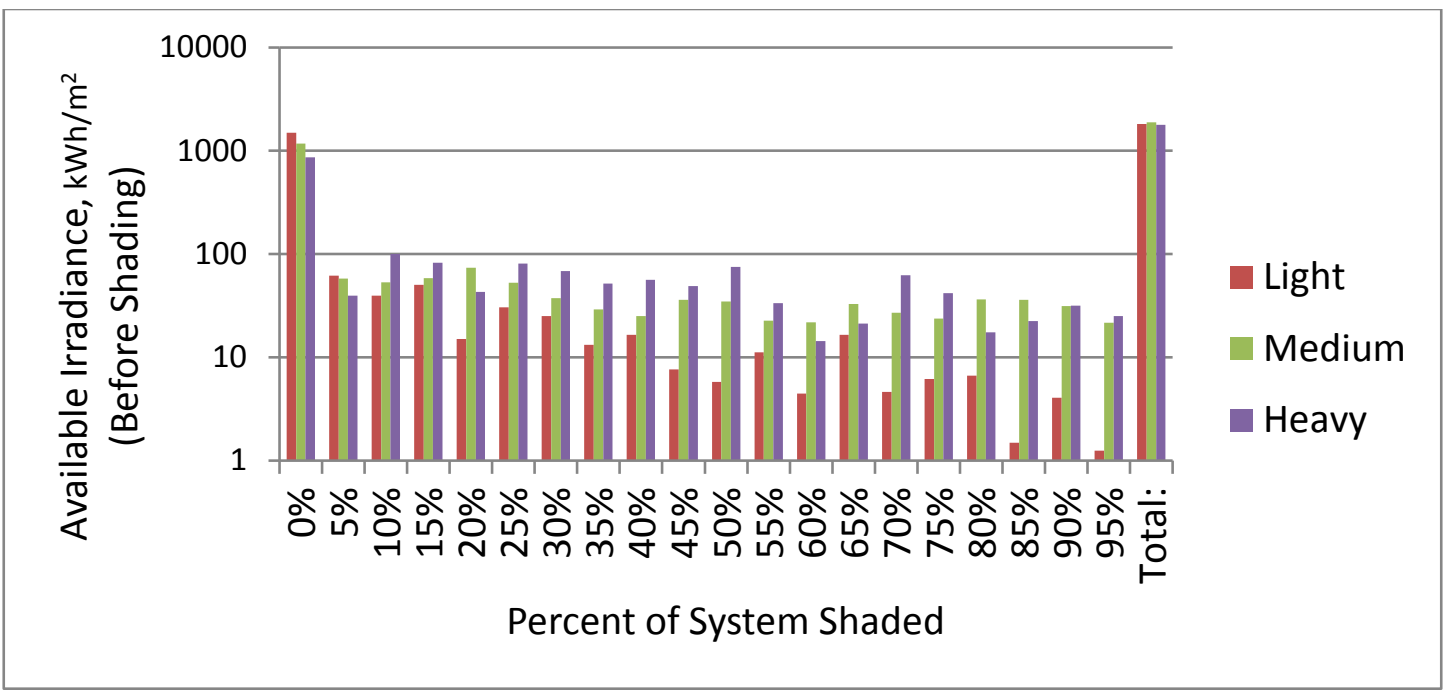

Figure 6. Shading histogram data from site surveys of three representative systems - Light, Medium and Heavy. The numerical values of this figure are reproduced in Appendix A.

\subsection{Weighting Shading Results by Residential Histogram}

The experimental Normalized Performance data of Fig. 4 and the residential histogram data of Fig. 6 are combined in the following way. Interpolation of experimental data creates values at system shading increments of 5\%, to match the bin values of Appendix A and Fig. 6. Values for $n$ assuming three parallel strings of 36 submodules (108 total submodules) are given in Table 2.

Table 2. Interpolated $n$ equivalents to match $5 \%$ system shading increments
( $n: 0: 0)$ shading
Two-string ( $n: n: 0)$ shading
Three-string (n:n:n) shading

\begin{tabular}{c|c|c|}
\hline \hline $\begin{array}{c}5 \%-30 \% \text { system } \\
\text { shade }\end{array}$ & String $1,2(5 \%-65 \%$ system shade) & String 1,2,3 (5\% - 95\% system shade) \\
\hline$n=5.4,10.8,16.2,21.6,27$, & $n=2.7,5.4,8.1,10.8,13.5,16.2,18.9,21.6$, & $n=1.8,3.6,5.4,7.2,9,10.8,12.6,14.4,16.2,18$, \\
32.4 & $24.3,27,29.7,32.4,35.1$ & $19.8,21.6,23.4,25.2,27,28.8,30.6,32.4,34.2$
\end{tabular}

Although 38 interpolated datapoints are given in Table 2, some of them correspond to the same system shading fraction. For instance, $5 \%$ system shading is achieved by the following three shading amounts: (5.4:0:0), (2.7:2.7:0) and (1.8:1.8:1.8). If multiple values exist for a given system shade fraction, the various values should be averaged ${ }^{1}$ to create one equivalent

\footnotetext{
${ }^{1}$ Different weighted averages were investigated with slight impact on the final performance score. Judging by Fig. 9 of [1], uniform shading is more prevalent than distributed shading in the moderate shading case. Because of this, the $n: 0: 0, n: n: 0$, and $n: n: n$ series are weighted in a ratio of 1:2:3. If only two strings are used in a comparison, the $n: 0$ and $n: n$ series are weighted in a ratio of $1: 2$.
} 
Normalized Performance score for each of the 5\% shading fractions from 5\%-95\%. Zero-shade conditions are assigned a Normalized Performance score of 1 by definition since the system must perform identically to itself in unshaded conditions.

The interpolated Normalized Performance values, averaged to one number for each 5\% shading bin are multiplied by the corresponding Annual Irradiance of Appendix A. These weighted performance scores are then summed to create the energy score for a given shading histogram (e.g., $E_{\text {Ref-Light }}$ or $\left.E_{D U T-H e a v y}\right)$. Unshaded Energy is the total unshaded irradiance summed over all histogram bins.

$$
\begin{gathered}
E_{X-X}=\sum_{0 \% \text { shade }}^{95 \% \text { shade }}(\text { Normalized Performance })_{X X} \times(\text { Irradiance per bin }) \\
E_{\text {unshaded }}=\sum_{0 \% \text { shade }}^{95 \% \text { shade }}(\text { Irradiance per } \mathrm{bin})
\end{gathered}
$$

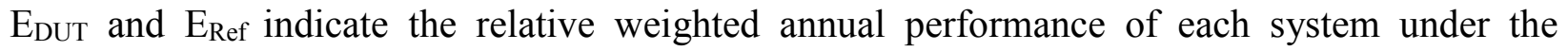
various shading conditions: light, moderate, and heavy.

To calculate the percentage of shading loss that can be recovered by the use of the DUT in a particular use scenario, a Shade Mitigation Factor (SMF) is determined from the relative difference between total Energy for the two systems. SMF is defined as follows:

$$
\text { Shade Mitigation Factor }(S M F)=\frac{E_{D U T}-E_{R e f}}{E_{\text {unshaded }}-E_{\text {Ref }}}
$$

An advantage of reporting the SMF value for a particular DUT is that its value does not depend very strongly on the extent of the shade being considered (light vs. heavy). An average value can be taken over the three shade histograms used in the analysis. This SMF value can then be used directly in performance modeling software such as PVWatts to compare the annual performance of a conventional inverter system versus one equipped with the DUT. If the annual shading loss is known from a site-survey tool, the correct annual shading derate value with use of the DUT is calculated as follows:

$$
\text { Annual Shade derate }=1-[(\text { Shade Loss } \%) *(1-S M F)]
$$

This is a rough approximation because there is uncertainty in the calculation of the SMF as well as the Shade Loss \%. Shading Loss is typically reported as a percentage of solar irradiance loss, rather than a percentage of electrical performance loss. As stated previously, Eq. (6) assumes a 1:1 correlation between a site survey's irradiance loss and the resulting PV electrical loss, which may not be an accurate assumption.

When using annual performance software, the conversion efficiency of the power electronics also needs to be considered. For string inverters or microinverters, the California Energy 
Commission (CEC) efficiency of the device is included in the annual performance calculation. For DC power optimizers, the CEC efficiency of the module-level converter is multiplied by the $\mathrm{CEC}$ efficiency of the string inverter to determine the overall DC-to-AC conversion efficiency.

Comparison with original analysis method: It should be noted than in the original publication of this methodology [1], the normalization method fit a linear function through all of the Normalized Performance data, rather than maintaining the nonlinear character of the Reference inverter data. This ignored the fact that different results existed for the same percentage of system shade, according to the distribution of the shade among the various strings. The methodology presented here is more representative of reality and yields more consistent (and lower) results than the original methodology.

The original methodology also reported a Performance Score for the DUT, defined as the annual energy improvement of the DUT system, vs. the Reference system.

$$
\text { Performance Score }=\frac{E_{D U T}}{E_{\text {Ref }}}
$$

This Performance Score may or may not be reported in the results of this method, because it neglects a number of important factors relevant to annual production such as the conversion efficiency of the DUT.

\subsection{Example Weighted Results}

When Eqs. (3-5) are applied to the original experimental results of Fig. 4, we can obtain weighted-average total Energy and Shade Mitigation Factor values for the example experimental data of Fig. 4.

Table 3. Summary of shade study results based on original Enphase M215 data

\begin{tabular}{|lccc|}
\hline \multicolumn{1}{|c}{ Parameter } & Light & Moderate & Heavy \\
\hline \% of System Shading & $7.6 \%$ & $19.0 \%$ & $25.5 \%$ \\
\hline Unshaded Energy $\left[\mathrm{kWh} / \mathrm{m}^{2}\right]$ & 1813 & 1893 & 1784 \\
\hline Enphase Energy $\left[\mathrm{kWh} / \mathrm{m}^{2}\right]$ & 1754 & 1699 & 1542 \\
\hline Reference Energy $\left[\mathrm{kWh} / \mathrm{m}^{2}\right]$ & 1718 & 1606 & 1408 \\
\hline Shade Mitigation Factor & $38 \%$ & $32 \%$ & $36 \%$ \\
\hline Average Shade Mitigation Factor & & $35 \%$ & \\
\hline
\end{tabular}

Comparison with original analysis method: The original analysis methodology returned a Performance Score that was somewhat higher than expected, as explained above. The following table describes the difference between the prior analysis method, and the current updated method, which returns a somewhat lower value. 
Table 4. Comparison between original analysis (Ref [1] table 10) and this updated analysis

\begin{tabular}{|lcc|}
\hline \multicolumn{1}{|c}{ Parameter } & Old analysis & New analysis \\
\hline Performance Score, Light & 1.04 & 1.02 \\
\hline Performance Score, Moderate & 1.08 & 1.06 \\
\hline Performance Score, Heavy & 1.12 & 1.095 \\
\hline Average Shade Mitigation Factor & $43 \%$ & $35 \%$ \\
\hline
\end{tabular}

The new analysis method provides results that are somewhat more consistent with independent experiments and simulations [8,9], showing Shade Mitigation Factors between 30\%-40\%, rather than the $40 \%-55 \%$ claimed before. In addition, the method is more repeatable and transparent, not relying on tables and multiplication factors of unknown origins.

\section{Additional experiment results using the current methodology}

Several additional experiments were conducted following the updated methodology of this shading test. Results are presented here and starting in Appendix D for multiple such experiments. Here, we compare Solar Edge power optimizer devices with Enphase M215 microinverters and a standard string inverter [10]. A second experiment investigates the shade response of submodule embedded converters under inter-row shading conditions. This submodule experiment features Maxim VT8012 module-embedded power converters, compared with a reference string inverter.

\subsection{Solar Edge, Enphase M215, and String Inverter test}

PV Evolution Labs (PVEL) of Davis, California, was contracted by Solar Edge to perform a test on a $6.24 \mathrm{~kW}$ Solar Edge system side-by-side with a comparable Enphase system, and a reference system using an SMA string inverter. Details of the three comparison systems are provided in Table 5 below. 
Table 5. System parameters for the two DUT arrays and the Reference array

\begin{tabular}{|c|c|c|c|}
\hline & Reference Array & Test Array \#1 & Test Array 2 \\
\hline Inverter & $\begin{array}{c}\text { SMA } \\
\text { SunnyBoy 6000US } \\
\text { (string inverter) }\end{array}$ & $\begin{array}{c}\text { SolarEdge } \\
\text { OP250-LV optimizers } \\
\text { with SE6000A-US } \\
\text { string inverter }\end{array}$ & $\begin{array}{c}\text { Enphase } \\
\text { M215 } \\
\begin{array}{c}\text { (single-module } \\
\text { inverter) }\end{array}\end{array}$ \\
\hline Grid Connection & \multicolumn{3}{|c|}{ 240-volt single-phase } \\
\hline Module & \multicolumn{3}{|c|}{ Sharp ND240QCJ } \\
\hline \# of Strings & \multicolumn{3}{|c|}{2} \\
\hline \# of Modules/String & \multicolumn{3}{|c|}{13} \\
\hline $\begin{array}{l}\text { Nameplate DC System } \\
\text { Power }\end{array}$ & \multicolumn{3}{|c|}{$6.24 \mathrm{~kW}$} \\
\hline CEC Efficiency & $95.5 \%$ & $98.8 \% * 97.5 \%$ & $96 \%$ \\
\hline System Location & \multicolumn{3}{|c|}{ PV-USA (Davis, CA) } \\
\hline System Orientation & \multicolumn{3}{|c|}{ 20-degree south-facing, portrait orientation } \\
\hline Testing Dates & \multicolumn{3}{|c|}{ June 19 to June 21, 2013} \\
\hline
\end{tabular}

In contrast with the results presented in [1] and in Fig. 4 above, the configuration considered here consists of two parallel strings of modules, rather than three parallel strings per system. As such, the results are not entirely comparable to the previous results. The Shade Mitigation Factor determined for a two-string system will tend to be lower than SMF for a three-string (or larger) system because the mismatch between parallel strings will be lower for the smaller system. However, the comparison includes the same Enphase M215 microinverter as previously used, which helps to benchmark the new experiment configuration against a three-string configuration.

Partial shading performance is monitored over 22 shading conditions as described in 2.1. With $13 \mathrm{PV}$ modules and 3 diodes per module, there are a total of 39 submodules per string. Because there are two parallel strings per system, the two shading configurations tested were $n: 0$ and $n: n$. 


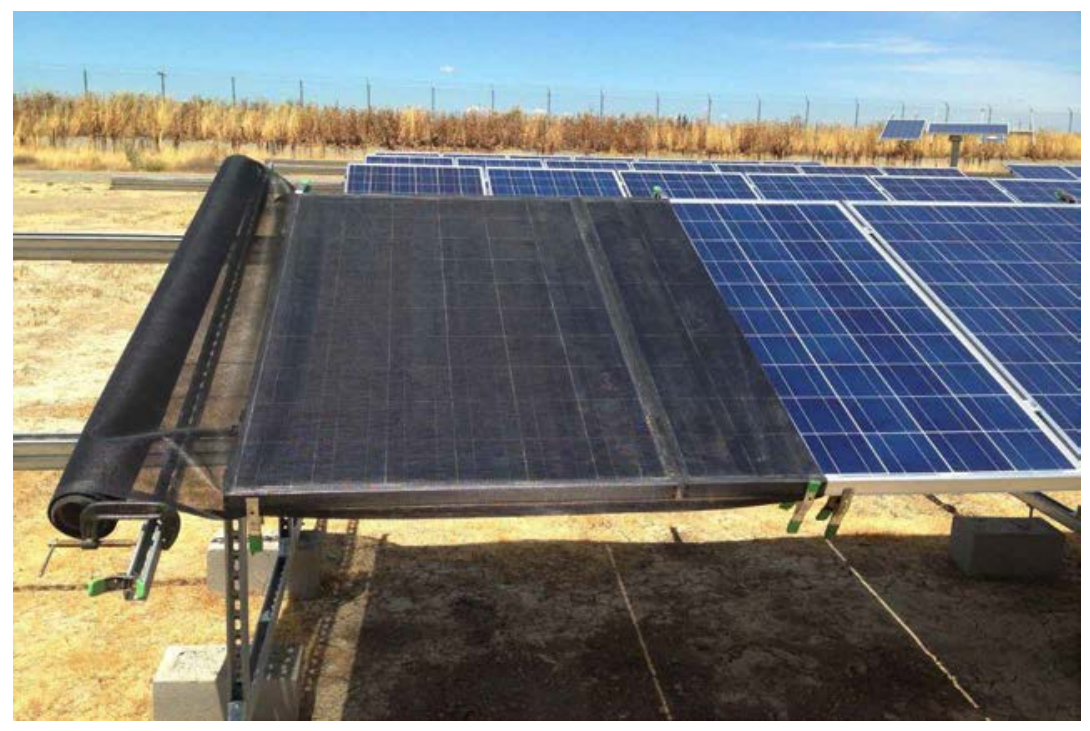

Figure 7. Close-up view of shading mesh on a single string.

The Normalized Performance of the two DUT systems and the Reference system are shown in Fig. 8, calculated by Eq. (2). The shaded results are compared with unshaded data, measured within three days of the shaded experiments. By translating data to STC conditions, as well as comparing against unshaded data at the same time of day, variable conditions such as temperature, irradiance, and differences in PV module nameplate rating are removed from the comparison.

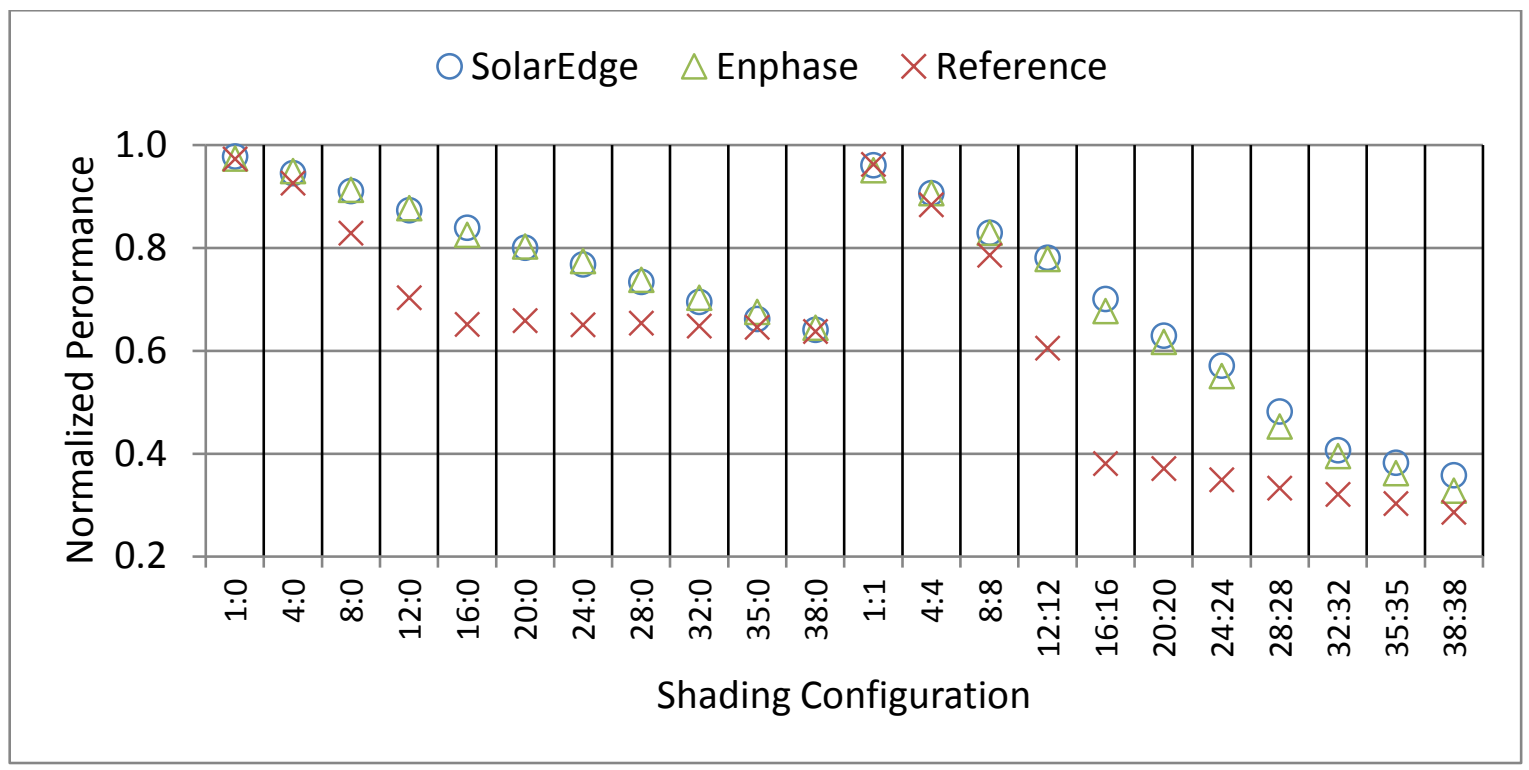

Figure 8. Normalized Performance of the three systems under 22 partial shading conditions.

Inspection of the Normalized Performance in Fig. 8 indicate that the SolarEdge and Enphase DUT arrays are closely matched, while the Reference array follows a similar nonlinear response to that of the Reference Array in Fig. 4. 
The above experimental results are analyzed according to the method described in Section 3.3. Namely, linear interpolation of data points match the $n: 0$ and $n: n$ results to the $5 \%$ shading bins of Appendix A. For $0 \%-50 \%$ system shading where both $n: 0$ and $n: n$ results contribute, the values are weighted with $n: n$ results counting for twice the value of $n: 0$ results. This weighted average is based on Fig. 9 of [1], which shows a greater proportion of uniform $(n: n)$ shading than isolated $(n: 0)$ shading; the sensitivity of the analysis to the weighting value is very small.

Following interpolation, the Normalized Performance is used to calculate total Energy and Shade Mitigation Factor for each system under different shading conditions, according to Eqs. (3-5). These results are provided in Table 6.

Table 6. Summary of shade study results - SolarEdge OP250 and Enphase M215

\begin{tabular}{|lccc|}
\hline \multicolumn{1}{|c}{ Parameter } & Light & Moderate & Heavy \\
\hline \% of System Shading & $7.6 \%$ & $19.0 \%$ & $25.5 \%$ \\
\hline Unshaded Energy $\left[\mathrm{kWh} / \mathrm{m}^{2}\right]$ & 1813 & 1893 & 1784 \\
\hline SolarEdge Energy $\left[\mathrm{kWh} / \mathrm{m}^{2}\right]$ & 1729 & 1616 & 1438 \\
\hline Enphase Energy $\left[\mathrm{kWh} / \mathrm{m}^{2}\right]$ & 1727 & 1610 & 1431 \\
\hline Reference Energy $\left[\mathrm{kWh} / \mathrm{m}^{2}\right]$ & 1696 & 1539 & 1328 \\
\hline Shade Mitigation Factor & $27-28 \%$ & $20-22 \%$ & $23-24 \%$ \\
\hline Average Shade Mitigation Factor & & $23-25 \%$ & \\
\hline
\end{tabular}

As expected, the close match of Normalized Performance data of Fig. 8 results in similar average SMF for the two DUT arrays: $23 \%$ for the Enphase array, and 25\% for the SolarEdge array. These values can be contrasted with the $35 \%$ average SMF value for the three-string experiment.

The difference in results between Table 3 and Table 6 can be explained by the size difference between the two experiments. The original comparison was conducted on a three-string system, in which case the use of module-level electronics resulted in the recovery of $35 \%$ of the shade losses. The greater shade-mitigation factor indicates that a larger portion of the shading losses are indirect losses from mismatch between parallel strings, as opposed to direct losses from irradiance reduction. Distributed electronics only recover losses due to mismatch, and an increased number of parallel strings increases the opportunity for mismatch between shaded and unshaded strings.

\section{Shading histograms for inter-row shading applications}

The previously described Light, Medium, and Heavy shade histograms are intended to replicate horizon shading on residential rooftops, e.g., from nearby tree or building obstructions. In the application considered here of inter-row shading, new shading histograms are required that are more representative of large, free-field installations. In this case, regular row spacing and rows 
of infinite length are assumed, as well as representative system configurations of 20-degree tilt and south-facing orientation.

In keeping with the spirit of the previous test configuration, three shading conditions are again chosen to represent partial shading from different row spacing. The representative shading conditions are defined by a ground coverage ratio (GCR), defined as the ratio of the PV array area to the total ground area. The three GCR values evaluated here are: $0.64,0.74$, and 0.8 .

Inter-row shading histograms are required for both portrait and landscape mounting orientations. Given the typical configuration of ground-mount systems, both 2-up portrait configuration, and 3-up landscape configuration were chosen for further analysis (Fig. 9). Both histograms assume infinite spatial extent in all directions to limit edge effects. Therefore, the fact that the first row of a PV system is unshaded is neglected from this analysis.
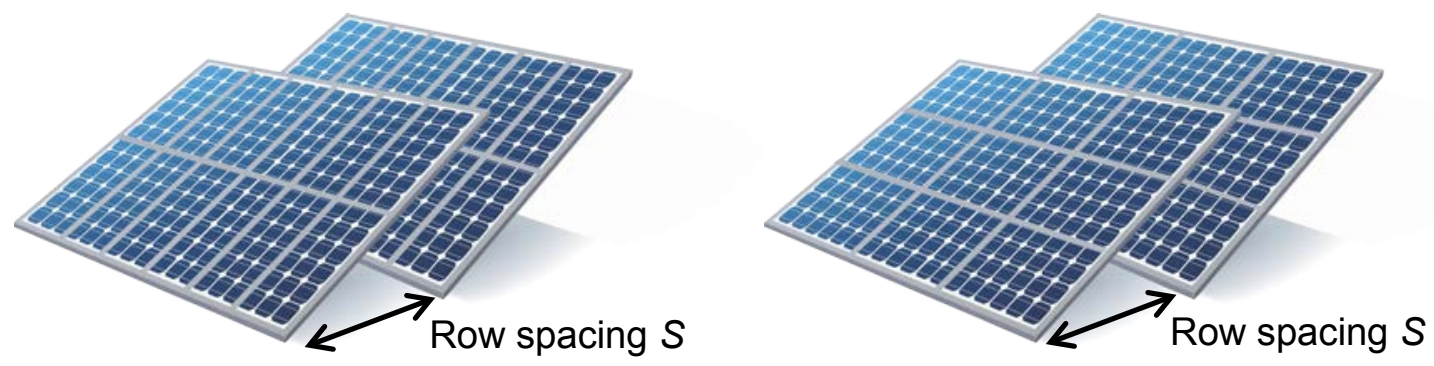

Figure 9: 2-up portrait configuration (left) and 3-up landscape configuration (right). Row spacing is defined from the front of one row to the front of the next.

Annual simulations were conducted in NREL's System Advisor Model to model the extent of shading loss, using the inter-row shade calculation function described in [11]. Array dimensions are calculated assuming a typical 60-cell PV module size of $1.65 \mathrm{~m} \times 0.99 \mathrm{~m}$ in either 2-up portrait or 3-up landscape orientation. A $0.5 \mathrm{MWac}$ central inverter was assumed, along with 150 parallel strings of $250 \mathrm{~W}$ panels at 20-degree fixed tilt, 180-degrees azimuth. Such a large installation was chosen to limit edge effects. The Sacramento TMY2 weather file was chosen as a representative meteorological dataset, as well.

Given the above parameters, simulations were conducted for three GCR values and two module orientations. Simulated shading loss is calculated relative to unshaded system performance, and separated into beam shading loss (transient opaque shading leading to large intra-panel mismatch) and diffuse loss (persistent small irradiance loss across the system due to reduced field-of-view of the diffuse sky dome). A detailed discussion of diffuse shading loss in this system is given in [12]. For the inter-row shading procedure considered here, only the beam shading loss is considered for recovery. The test methodology does not allow the extremely slight mismatch from diffuse irradiance loss to be monitored or measured for recovery. Even if the DUT were to recover some of this type of diffuse irradiance mismatch, the experimental methodology is not set up to capture it. Therefore, the resulting Shade Mitigation Factor considers only the recovery of beam shading loss, not beam + diffuse shading loss. 
It can be seen that the various shading simulations result in total annual estimated losses between $4 \%$ and $14 \%$, with the beam shading loss accounting for roughly half of the total loss. Note that these simulated values are specific to the orientation and weather data assumed above.

Table 7. Inter-row shading configuration and beam shading loss (Reference system)

\begin{tabular}{|lccc|}
\hline \multicolumn{1}{|c}{ Parameter } & GCR:0.64 & GCR:0.74 & GCR:0.8 \\
\hline Row spacing (landscape) [m] & 4.6 & 4.0 & 3.7 \\
\hline Row spacing (portrait) [m] & 5.1 & 4.5 & 4.1 \\
\hline Annual beam loss (3x landscape) & $1.5 \%$ & $3.7 \%$ & $5.7 \%$ \\
\hline Annual diffuse loss (3x landscape) & $2 \%$ & $3.7 \%$ & $5.3 \%$ \\
\hline Annual beam loss (2x portrait) & $2.3 \%$ & $5.6 \%$ & $8.6 \%$ \\
\hline Annual diffuse loss (2x portrait) & $2 \%$ & $3.7 \%$ & $5.3 \%$ \\
\hline
\end{tabular}

More detailed beam-shading histograms are calculated based on [13] and hourly solar position and irradiance values from the Sacramento, CA TMY2 dataset. As before, the hourly histogram of shade extent is weighted by the unshaded POA irradiance during that period of time. Figure 10 shows the annual histogram of shade extent for each of the three GCR values, in the 2-up portrait configuration. The annual irradiance for this simulation is $1993 \mathrm{kWh} / \mathrm{m}^{2}$, with the majority of that irradiance occurring under unshaded conditions. At higher GCR values, greater amounts of shading occur.

It is interesting to note that $100 \%$ system shading accounts for the same $\mathrm{kWh} / \mathrm{m}^{2}$ value in this histogram, regardless of GCR value. Shading of the entire system occurs only at sunrise and sunset, when shadows are cast far enough to shade everything regardless of row spacing.

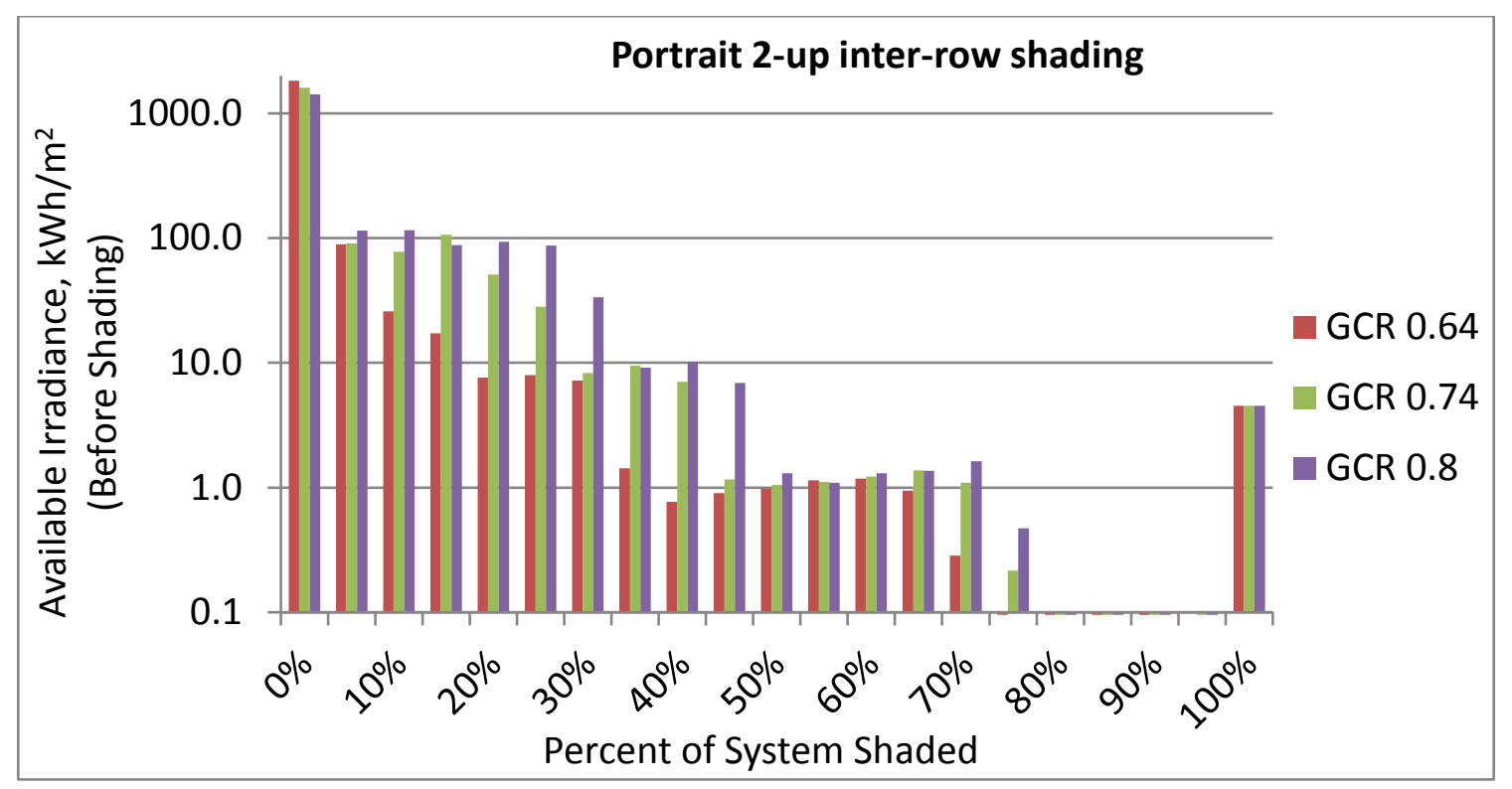

Figure 10. Shading histogram data for 2-up portrait inter-row shading. The numerical values of this figure are reproduced in Appendix B. 
In practice, 2-up portrait shading performance data requires two strings connected in parallel to the same string inverter. Because shading is applied artificially, modules do not need to be physically mounted in a 2-up portrait configuration - the two strings can be located in separate rows and shaded separately. The first string is considered to be the "bottom" string and is shaded along its entire length (all modules). It may be easier to drape the shading fabric from the top edge of the modules down, rather than pulling from the bottom up. Either way, the shading fabric is pulled down (or up) along all of string \#1 in 10\% module height increments.

At the 50\% system shade condition, the first string is fully covered by the shading fabric. For performance data from $50 \%$ to $100 \%$ system shading, the first string is kept fully shaded, and shading fabric is next applied to string \#2 in 10\% height increments until it too is fully shaded.

A similar shading histogram is generated for the 3-up landscape system configuration (Appendix C). Because there are three modules high instead of two modules, the first module is fully shaded at $33 \%$ system shading, rather than $50 \%$ system shading.

Diffuse irradiance component: The previous shading methodology used a shading fabric with 0.36 measured transmittance (McMaster-Carr $\mathrm{P} / \mathrm{N}$ 87655K134). This fabric was chosen to maintain a diffuse fraction of irradiance that is less than $50 \%$. Although this choice was appropriate for the horizon and obstruction shading conditions of residential rooftops, the diffuse fraction of irradiance is somewhat greater for inter-row shading conditions. The ratio of Diffuse irradiance to Global irradiance $(\mathrm{D} / \mathrm{G})$ ranges from $\mathrm{D} / \mathrm{G}=0.3$ at unshaded conditions to $\mathrm{D} / \mathrm{G} \approx 1$ at large amounts of system shading (Fig. 11).

Annual weighted averages of $\mathrm{D} / \mathrm{G}$ (neglecting unshaded conditions) for the greatest row spacing $(\mathrm{GCR}=0.64)$ are $\mathrm{D} / \mathrm{G}=0.55$. This is considerably higher than the 0.36 transmittance value of the shading fabric used for the residential shading test. A different shading fabric is proposed here with a higher measured transmittance: McMaster-Carr P/N 88275K39 with a measured transmittance of 0.62 . This type of fabric is considered to be more appropriate for the more diffuse shade conditions experienced during inter-row shading. 


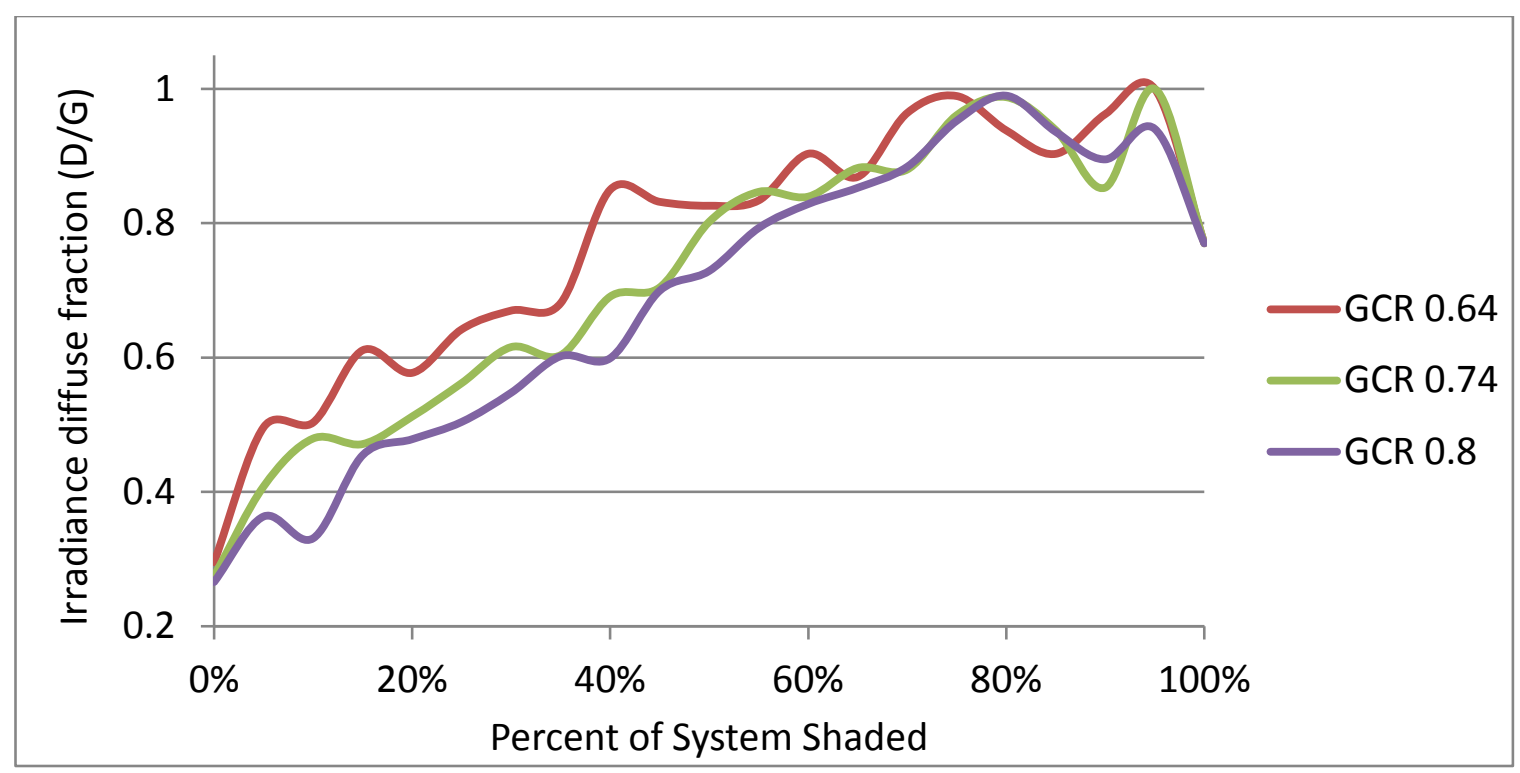

Figure 11. Weighted diffuse fraction (D/G) for inter-row shading. The overall annual weighted diffuse fraction is $D / G=0.55$ for $G C R=0.64$. Other annual weighted values are $D / G=0.49$ and $D / G=$ 0.44 for $\mathrm{GCR}=0.74$ and $\mathrm{GCR}=0.8$, respectively. Results are identical for portrait and landscape configurations.

\subsection{Results: Maxim sub-module converters}

The above methodology for inter-row shading comparison was verified on a field installation at NREL's Regional Test Center site in Aurora, CO. The Device Under Test is the Maxim VT8012 embedded electronic module, which uses six DC-DC converters per 72-cell panel. This embedded module is designed to reduce inter-row shading losses when installed in portrait configuration, so the 2-up portrait shading histogram of Appendix B is used in this experiment. More details on this technology can be found in [12].

The VT8012 embedded devices are built around a standard JA Solar 300W panel, integrated at the factory. Two parallel strings of 10 panels each are used in the DUT array (with VT8012 chips embedded) and the Reference array (without VT8012 chips).

Both the DUT array and the Reference array are connected to conventional string inverters (Power-One PVI-6000) to provide DC-to-AC conversion. String-level performance is monitored by independent current and voltage transducers, as well as calibrated onboard inverter monitoring. 
Table 8. System parameters for the DUT array and the Reference array

\begin{tabular}{|c|c|c|}
\hline & Reference Array & DUT Array \\
\hline Inverter & $\begin{array}{l}\text { Power-One } \\
\text { PVI-6000-US } \\
\text { (string inverter) }\end{array}$ & $\begin{array}{c}\text { Maxim VT8012 embedded DC } \\
\text { converters with PVI-6000-US } \\
\text { string inverter }\end{array}$ \\
\hline Grid Connection & \multicolumn{2}{|c|}{ 277-volt single-phase } \\
\hline Module & \multicolumn{2}{|c|}{ JA Solar JAP6-72-300-3BB } \\
\hline \# of Strings & \multicolumn{2}{|r|}{2} \\
\hline \# of Modules/String & \multicolumn{2}{|r|}{10} \\
\hline $\begin{array}{l}\text { Nameplate DC System } \\
\text { Power }\end{array}$ & \multicolumn{2}{|r|}{$6 \mathrm{~kW}$} \\
\hline CEC Efficiency & $96.5 \%$ & $96.5 \% *$ \\
\hline System Location & \multicolumn{2}{|c|}{ Aurora, CO } \\
\hline System Orientation & \multicolumn{2}{|c|}{ 30-degree south-facing, portrait orientation } \\
\hline Testing Dates & \multicolumn{2}{|c|}{ April 8 to April 14, 2014} \\
\hline
\end{tabular}

*DUT conversion efficiency is included in the $300 \mathrm{~W}$ factory flash value of the PV module

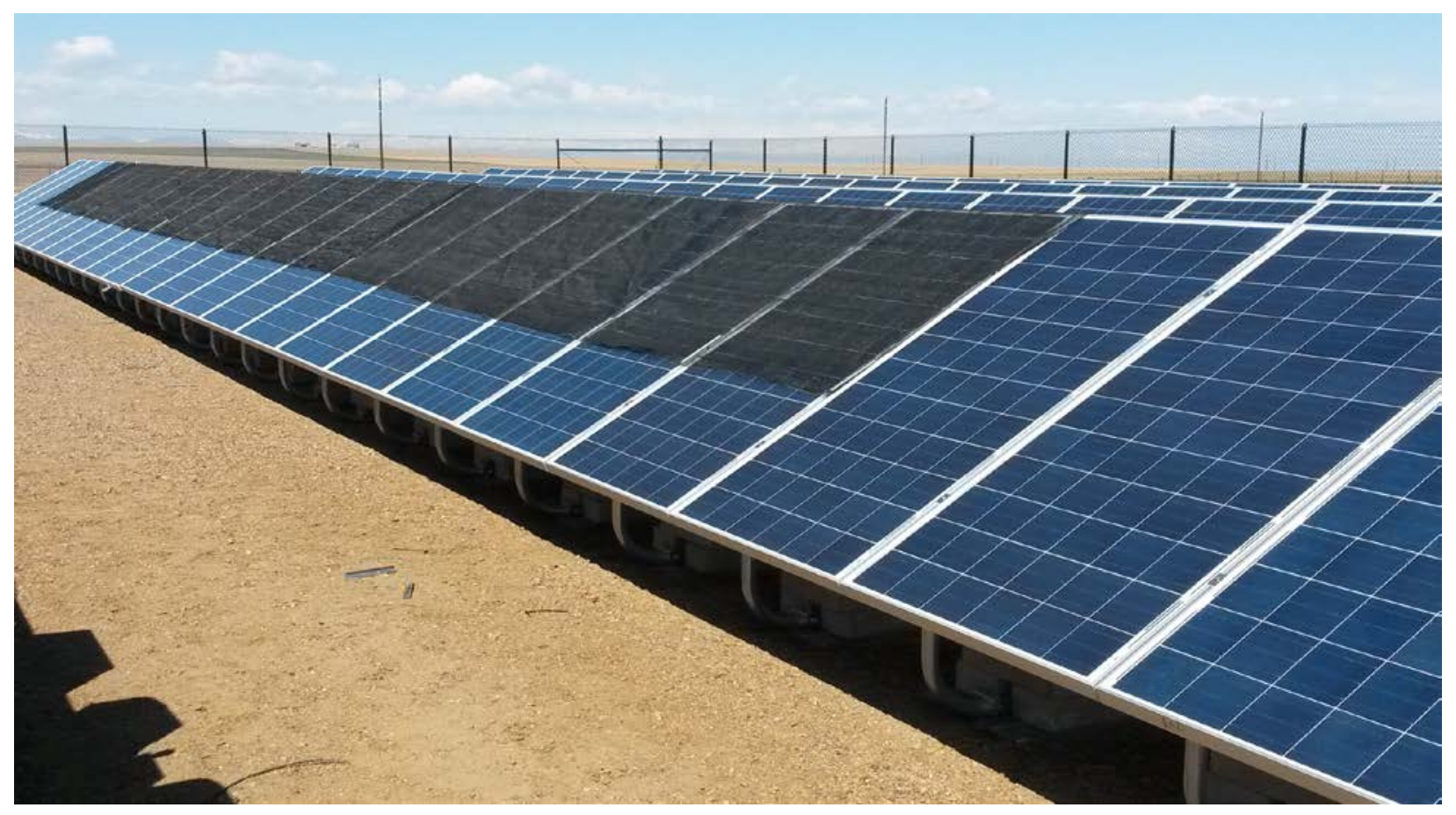

Figure 12: Maxim installation at the Aurora, CO, site (Unshaded panels in the foreground are not included in the partial-shade experiment). 
Direct shading was applied using the $62 \%$ transparent mesh suggested above (McMaster-Carr $\mathrm{P} / \mathrm{N}$ 88275K39). Unshaded measurements were collected over a full day. A total of 14 partial shading configurations were collected in 10-min intervals over the next several days. Shading fabric was extended over the entire length of String \#1 of the DUT array and the Reference array, and lowered in increments of 1.5 cells $(12.5 \%)$. Once the first string of each array is fully covered, the second string is shaded in $12.5 \%$ increments until both strings of both arrays are fully covered. The raw data are aligned with the $10 \%$ interval of Appendix B by linear interpolation.

All data were acquired under clear-sky conditions with POA irradiance greater than $500 \mathrm{~W} / \mathrm{m}^{2}$. The mesh was applied and a wait time of several minutes was allowed to ensure that the inverters stabilize prior to collecting energy data. Normalized Performance results are given in Fig. 13. The results are consistent with the Maxim-equipped system responding in a linear fashion to increased amounts of shade, whereas the Reference system has a very large performance reduction when partial shading is introduced. In this particular comparison where shading is applied horizontally across all substrings of the Reference system, any amount of shading on a particular string results in a very large drop in performance. For instance, a large performance drop occurs from $0 \%$ to $6.25 \%$ system shading when String 1 is just beginning to be shaded, and from $50 \%$ to $56.25 \%$ shading when String 2 is just beginning to be shaded.

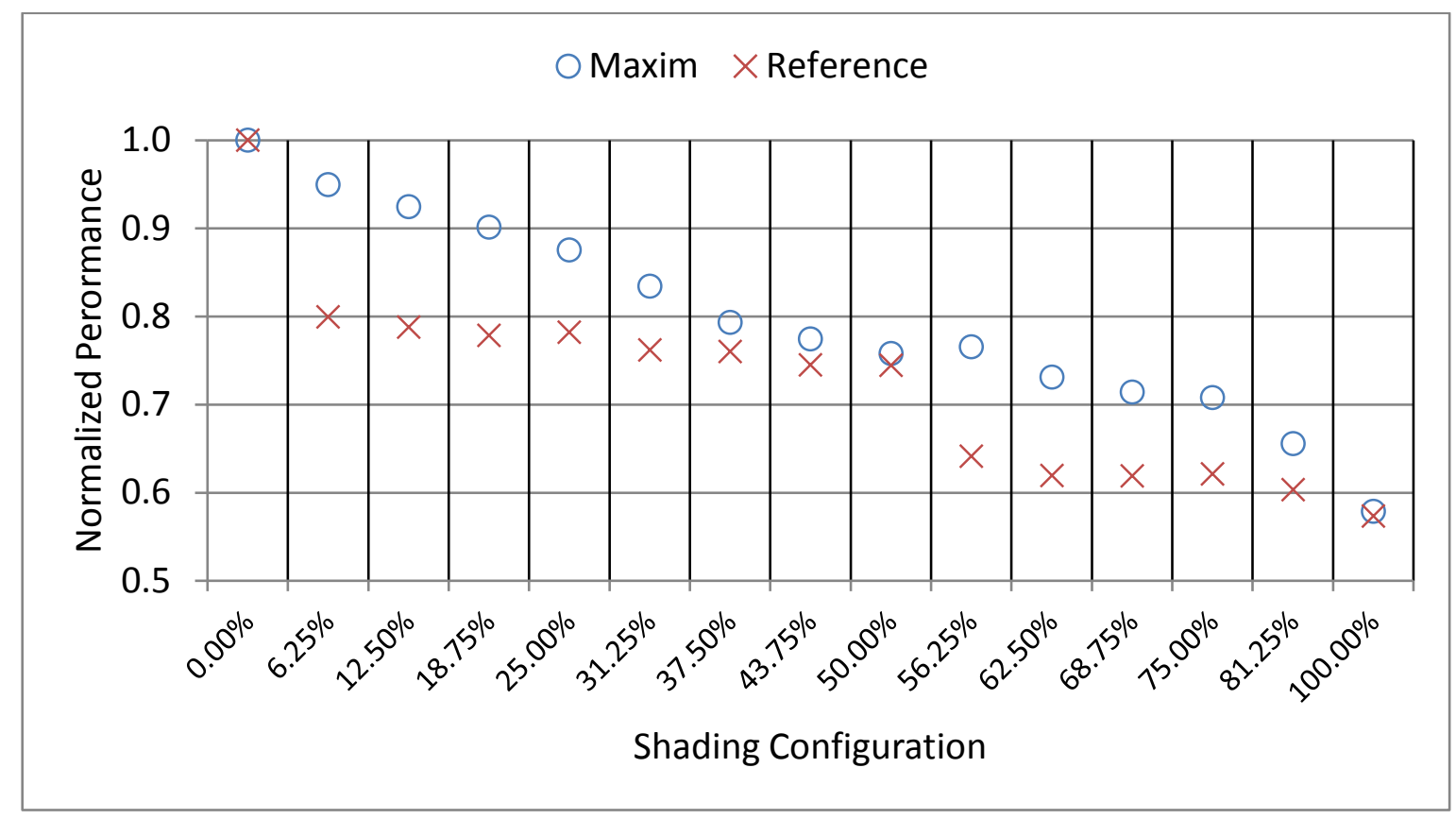

Figure 13. Normalized Performance of the Maxim VT8012 system and Reference system under 2up portrait inter-row shading.

Following linear interpolation, the performance results are weighted by the irradiance histogram values shown in Appendix B for the 2-up portrait configuration. Results are given in Table 9, including a Shade Mitigation Factor for the beam shading loss. 
Table 9. Summary of shade study results - Maxim 2-up portrait

\begin{tabular}{|lccc}
\hline \multicolumn{1}{c}{ Parameter } & GCR:0.64 & GCR:0.74 & GCR:0.8 \\
\hline Modeled beam loss (Reference) & $-2.3 \%$ & $-5.6 \%$ & $-8.6 \%$ \\
\hline Modeled diffuse loss (Reference) & $-2.0 \%$ & $-3.7 \%$ & $-5.3 \%$ \\
\hline Unshaded Energy $\left[\mathrm{kWh} / \mathrm{m}^{2}\right]$ & 1988 & 1988 & 1988 \\
\hline Maxim Energy $\left[\mathrm{kWh} / \mathrm{m}^{2}\right]$ & 1975 & 1954 & 1934 \\
\hline Reference Energy $\left[\mathrm{kWh} / \mathrm{m}^{2}\right]$ & 1953 & 1905 & 1866 \\
\hline Actual beam loss (Reference) & $-1.7 \%$ & $-4.2 \%$ & $-6.2 \%$ \\
\hline Actual beam loss (Maxim) & $-0.6 \%$ & $-1.7 \%$ & $-2.7 \%$ \\
\hline Shade Mitigation Factor & $64.1 \%$ & $59.1 \%$ & $55.9 \%$ \\
\hline Average Shade Mitigation Factor & & $60 \%$ & \\
\hline
\end{tabular}

The Shade Mitigation Factor of the VT8012 Maxim integrated power electronics is very good in this application, resulting in a recovery of $\sim 60 \%$ of the beam shading loss. One reason for this large performance benefit is the particularly high loss that occurs in the Reference system. For conventional modules in portrait orientation, inter-row shading is oriented perpendicular to the orientation of the bypass-diode submodules. Consequently, all modules are equally shaded, and bypass diodes are not providing any performance benefit. If the reference modules were instead oriented in landscape rather than in portrait, the Reference system shading loss would likely be lower, as would Maxim's calculated SMF value.

As previously stated, this experimental procedure is unable to assess the slight and persistent mismatch from diffuse irradiance screening. It is expected that the DUT would have a reduced ability to mitigate such a small mismatch, but this is speculation because the effect has not been assessed. In a worst-case scenario where the diffuse irradiance loss is included in the SMF calculation, but no additional performance benefit is provided by the DUT, the overall shade recovery is $\sim 35 \%$. This reflects the fact that beam shading loss accounts for slightly over half of the total shading loss simulated in the reference system.

From inspection of Table 9, a comparison can be made between the modeled and experimental beam shading losses. The modeled beam losses for the Reference system are slightly higher than what was determined by following the partial-shading procedure. For instance, at GCR $=0.8$, modeled beam shading loss for the Reference system is $-8.6 \%$, but the experimental results show only a $-6.2 \%$ actual shading loss. This slight discrepancy could likely be corrected by the use of a more opaque shading fabric during the partial shading experiment. It was originally calculated that a $62 \%$ transparent shading fabric would be more appropriate than the $37 \%$ transparent fabric used before. However, preliminary estimates suggest that the use of the more opaque shading fabric would result in a greater experimental shading loss, bringing experimental shading losses more in line with the modeled annual shading losses. Preliminary estimates have the $37 \%$ transparent fabric increasing the experimental losses to $-9 \%$ for GCR: 0.8 . However, the SMF value is predicted to remain essentially unchanged, because shading losses will increase in both the Reference system and the Maxim system. Based on this assumption, either the $62 \%$ transparent or the $37 \%$ transparent shading fabric would be adequate for this type of shading test. 


\section{Conclusion}

The original NREL Partial-Shading Test Procedure has been updated, bringing experimental results more in line with modeled behavior of module-level power electronics, and making the test procedure more robust and repeatable. An analysis was conducted of how these updates affect initially published performance results, slightly reducing the expected performance benefit of distributed electronics. Additional performance results are detailed for electronics manufacturers including Solar Edge. Results collected to date indicate that Shade Mitigation Factor (SMF) values range between $25 \%$ and $35 \%$, depending on the number of parallel strings in the test array (two or three). Only slight performance differences were apparent between the different module-level electronics under test.

A new test protocol and weighting histogram has been provided for the investigation of inter-row shading losses. An initial application of the protocol using Maxim Integrated VT8012 panels in portrait configuration shows that $60 \%$ of beam shading losses can be recovered from the use of this embedded technology. A caveat should be stated that the method described here is not suitable to assess the very slight but persistent performance loss arising from field-of-view reduction of diffuse irradiance. An additional performance improvement might be achieved from devices in the field if this type of mismatch could be monitored.

Additionally, the orientation of the PV modules has a large impact on the system performance; the use of a landscape orientation would have a different, likely lower, SMF score for this particular technology.

Further performance results will be continuously updated, beginning in Appendix D for partner experiments occurring after initial publication of this technical report.

We hope that the test methodology described here can be of use at different test installations or by equipment manufacturers to gauge the benefit of their equipment in these various applications. In particular, the Shade Mitigation Factor can be of particular value to consumers evaluating performance benefits of distributed power electronics, relative to conventional equipment. Combined with the CEC efficiency of the device (or the CEC efficiency of the inverter upstream of the device), this SMF score provides an annual derate that could be used in many PV simulation programs such as NREL's PVWatts or SAM to more accurately predict annual system performance.

\section{Acknowledgements}

Test data included here were collected under test service agreements between PV Evolution Laboratory, Enphase Energy, and Solar Edge. Testing methods were developed and data analysis was independently conducted by the National Renewable Energy Laboratory under Contract No. DOE-AC36-08GO28308 with the Department of Energy. Maxim Integrated performance data were collected under a Cooperative Research and Development Agreement with the Department of Energy's Regional Test Centers. Testing was conducted at PV Evolution Labs by Rajeev Singh, Filiberto Alex Pineda, and Dang H. Dang. Additional performance data included in the Appendices may be covered under additional agreements. 


\section{References}

1. C. Deline, J. Meydbray, M. Donovan, J. Forrest, Photovoltaic (PV) Shading Testbed for Module-level Power Electronics, NREL Report No. TP-5200-54876. Golden, CO: National Renewable Energy Laboratory, May 2012. http://www.nrel.gov/docs/fy12osti/54876.pdf

2. C. Deline, B. Marion, J. Granata, S. Gonzalez. A Performance and Economic Analysis of Distributed Power Electronics in Photovoltaic Systems. NREL Report No. TP-5200-50003. Golden, CO: National Renewable Energy Laboratory, December 2010. http://www.nrel.gov/docs/fy11osti/50003.pdf.

3. California Energy Commission. New Solar Homes Partnership Committee Final Guidebook. Report CEC-300-2006-017-CTF. Sacramento, CA: California Energy Commission, November 2006; p. 25. http://www.energy.ca.gov/2006publications/CEC-300-2006-017/CEC-300-2006017-CTF.PDF.

4. California Energy Commission. 2009 California Residential Appliance Saturation Study, Vol. 2. Sacramento, CA: California Energy Commission, October 2010; p. 13. http://www.energy.ca.gov/2010publications/CEC-200-2010-004/CEC-200-2010-004-V2.PDF.

5. BEW Engineering Inc. Draft Evaluation Approach for Shade Impact Mitigation Devices. Contractor report prepared for the California Energy Commission, June 3, 2009 (unpublished).

6. M.C. Alonso-Garcia, J.M. Ruiz, F. Chenlo, "Experimental study of mismatch and shading effects in the I-V characteristic of a photovoltaic module", Solar Energy Materials \& Solar Cells; Vol. 90, 2006; pp.329-340

7. Solmetric Inc. “Application Note: Understanding the Solmetric SunEye.” March 2011. http://resources.solmetric.com/get/UnderstandingTheSolmetricSunEye-March2011.pdf.

[8] MacAlpine, S., Erickson, R., \& Brandemuehl, M. (2013). Characterization of power optimizer potential to increase energy capture in photovoltaic systems operating under nonuniform conditions. IEEE Transactions on Power Electronics, 28(6), 2936-2945.

[9] Hanson A, Deline C, MacAlpine S, Stauth J, Sullivan C, "Partial-Shading Assessment of Photovoltaic Installations via Module-Level Monitoring", IEEE Journal of Photovoltaics 2014 (in review)

[10] Solar Edge white paper "Performance of PV Topologies under Shaded Conditions", July 2013

http://www.solaredge.com/files/pdfs/performance_of_pv_topologies_under_shaded_conditions.p df

[11] Deline C, Dobos A, Janzou S, Meydbrey J, Donovan M. (2013) "A simplified model of uniform shading in large photovoltaic arrays" Solar Energy 96, 274-282

[12] C. Deline, B. Sekulic, J. Stein, S. Barkaszi, J. Yang, S. Kahn, "Evaluation of Maxim Module-Integrated Electronics at the DOE Regional Test Centers", proceedings of the 40th IEEE Photovoltaic Specialist Conference, 2014, http://www.nrel.gov/docs/fy14osti/62024.pdf

[13] J Appelbaum, J. Bany, "Shadow effect of adjacent solar collectors in large scale systems". Solar Energy 23, 497-507 1979 


\section{Additional Bibliography}

M. Gross, S. Martin, N. Pearsall. "Estimation of Output Enhancement of a Partially Shaded BIPV Array by the Use of AC Modules." $26^{\text {th }}$ IEEE Photovoltaic Specialists Conference, Anaheim, CA, 1997.

A. Woyte, J. Nijs, R. Belmans. "Partial Shadowing of PV Arrays with Different System Configurations: Literature Review and Field Test Results." Solar Energy; Vol. 74, 2003; pp. 217-233.

N. Chaintreuil, F. Barruel, X. Le Pivert, H. Buttin, J. Merten. "Effects of Shadow on a Grid Connected PV System." 23 ${ }^{\text {rd }}$ European Photovoltaic Solar Energy Conference and Exhibition, 2008; p. 3417.

C. Deline. "Partially Shaded Operation of a Grid-Tied Photovoltaic System." $34^{\text {th }}$ IEEE Photovoltaic Specialists Conference, Philadelphia, PA, 2009.

S. MacAlpine, M. Brandemuehl, R. Erickson. "Analysis of Potential for Mitigation of BuildingIntegrated PV Array Shading Losses Through the Use of Distributed Power Converters." ASME $4^{\text {th }}$ International Conference on Energy Sustainability, Phoenix, AZ, 2010.

C. Deline. "Characterizing Shading Losses on Partially Shaded PV Systems." PV Performance Modeling Workshop, Albuquerque, NM, 2010. NREL Report No. PR-5200-49504.

B. Burger, B. Goeldi, S. Rogalla, H. Schmidt. "Module Integrated Electronics - An Overview." $25^{\text {th }}$ European Photovoltaic Solar Energy Conference and Exhibition, Valencia, Spain, 2010.

P. Tsao. "Simulation of PV Systems with Power Optimizers and Distributed Power Electronics." IEEE Photovoltaic Specialists Conference, Honolulu, HI, 2010.

S. MacAlpine, M. Brandemuehl, L. Linares, R. Erickson. "Effect of Distributed Power Conversion on the Annual Performance of Building-Integrated PV Arrays with Complex Roof Geometries." ASME $3^{\text {rd }}$ International Conference on Energy Sustainability, San Francisco, CA, 2009.

A. Kimber, L. Mitchell, S. Nogradi, H. Wenger. "The Effect of Soiling on Large Grid-Connected Photovoltaic Systems in California and the Southwest Region of the United States." IEEE $4^{\text {th }}$ World Conference on Power Conversion, Waikoloa, HI, 2006.

S. Poshtkouhi, et al., "A General Approach for Quantifying the Benefit of Distributed Power Electronics for Fine Grained MPPT in Photovoltaic Applications using 3D Modeling," IEEE Transactions on Power Electronics, in press; doi: 10.1109/TPEL.2011.2173353 


\section{Appendix A: Shading histogram data - Residential Shading}

\begin{tabular}{|c|c|c|c|}
\hline \multirow{2}{*}{$\begin{array}{c}\text { \% System } \\
\text { Shade }\end{array}$} & \multicolumn{3}{|c|}{ Annual Irradiance (kWh/m²) } \\
\hline & Light & Medium & Heavy \\
\hline $0 \%$ & 1490.85 & 1180.17 & 866.45 \\
\hline $5 \%$ & 61.88 & 57.67 & 39.62 \\
\hline $10 \%$ & 39.43 & 53.11 & 100.54 \\
\hline $15 \%$ & 50.20 & 58.68 & 82.15 \\
\hline $20 \%$ & 15.01 & 73.83 & 42.96 \\
\hline $25 \%$ & 30.41 & 52.93 & 80.99 \\
\hline $30 \%$ & 25.21 & 37.45 & 68.64 \\
\hline $35 \%$ & 13.26 & 29.18 & 51.97 \\
\hline $40 \%$ & 16.48 & 25.01 & 56.08 \\
\hline $45 \%$ & 7.62 & 35.92 & 49.17 \\
\hline $50 \%$ & 5.76 & 34.84 & 74.89 \\
\hline $55 \%$ & 11.16 & 22.71 & 33.53 \\
\hline $60 \%$ & 4.47 & 21.74 & 14.41 \\
\hline $65 \%$ & 16.55 & 32.99 & 21.19 \\
\hline $70 \%$ & 4.62 & 27.11 & 62.55 \\
\hline $75 \%$ & 6.18 & 23.73 & 41.99 \\
\hline $80 \%$ & 6.63 & 36.38 & 17.51 \\
\hline $85 \%$ & 1.49 & 36.22 & 22.43 \\
\hline $90 \%$ & 4.07 & 31.26 & 31.57 \\
\hline $95 \%$ & 1.25 & 21.55 & 25.04 \\
\hline
\end{tabular}

Table A1: Tabulated values for partial shading irradiance shown in Fig. 5, matched to a $5 \%$ bin frequency (the bin label represents the minimum value in the bin) 


\section{Appendix B: Shading histogram data - Inter-row Shading (Portrait 2-up)}

\begin{tabular}{|c|c|c|c|}
\hline \multirow{2}{*}{$\begin{array}{l}\text { \% System } \\
\text { Shade }\end{array}$} & \multicolumn{3}{|c|}{ Annual Irradiance $\left(\mathrm{kWh} / \mathrm{m}^{2}\right)$} \\
\hline & GCR: 0.6 & GCR: 0.7 & GCR: 0.75 \\
\hline $0 \%$ & 1825.4 & 1602.0 & 1421.9 \\
\hline $5 \%$ & 88.9 & 90.4 & 115.0 \\
\hline $10 \%$ & 25.9 & 77.7 & 116.0 \\
\hline $15 \%$ & 17.2 & 106.5 & 87.8 \\
\hline $20 \%$ & 7.6 & 51.0 & 93.2 \\
\hline $25 \%$ & 8.0 & 28.1 & 87.1 \\
\hline $30 \%$ & 7.2 & 8.3 & 33.6 \\
\hline $35 \%$ & 1.4 & 9.5 & 9.1 \\
\hline $40 \%$ & 0.8 & 7.1 & 10.2 \\
\hline $45 \%$ & 0.9 & 1.2 & 6.9 \\
\hline $50 \%$ & 1.0 & 1.0 & 1.3 \\
\hline $55 \%$ & 1.1 & 1.1 & 1.1 \\
\hline $60 \%$ & 1.2 & 1.2 & 1.3 \\
\hline $65 \%$ & 0.9 & 1.4 & 1.4 \\
\hline $70 \%$ & 0.3 & 1.1 & 1.6 \\
\hline $75 \%$ & 0 & 0.2 & 0.5 \\
\hline $80 \%$ & 0 & 0 & 0.1 \\
\hline $85 \%$ & 0 & 0 & 0 \\
\hline $90 \%$ & 0 & 0 & 0 \\
\hline $95 \%$ & 0 & 0 & 0 \\
\hline $100 \%$ & 4.5 & 4.5 & 4.5 \\
\hline
\end{tabular}

Table B1: Tabulated values for 2-up portrait inter-row shading shown in Fig. 10, matched to a $5 \%$ bin frequency (the bin label represents the maximum value in the bin) 


\section{Appendix C: Shading histogram data - Inter-row Shading (Landscape 3-up)}

\begin{tabular}{|c|c|c|c|}
\hline \multirow{2}{*}{$\begin{array}{c}\text { \% System } \\
\text { Shade }\end{array}$} & \multicolumn{3}{|c|}{ Annual Irradiance $\left(\mathrm{kWh} / \mathrm{m}^{2}\right)$} \\
\hline & GCR: 0.6 & GCR: 0.7 & GCR: 0.75 \\
\hline $0 \%$ & 1827.0 & 1594.1 & 1415.8 \\
\hline $5 \%$ & 87.5 & 93.6 & 118.6 \\
\hline $10 \%$ & 26.0 & 79.4 & 113.0 \\
\hline $15 \%$ & 17.0 & 101.3 & 89.1 \\
\hline $20 \%$ & 7.7 & 58.1 & 92.7 \\
\hline $25 \%$ & 8.1 & 29.1 & 91.4 \\
\hline $30 \%$ & 7.0 & 8.3 & 33.6 \\
\hline $35 \%$ & 1.4 & 9.2 & 8.6 \\
\hline $40 \%$ & 0.8 & 7.6 & 10.5 \\
\hline $45 \%$ & 0.9 & 1.3 & 7.4 \\
\hline $50 \%$ & 1.0 & 1.0 & 1.3 \\
\hline $55 \%$ & 1.1 & 1.1 & 1.1 \\
\hline $60 \%$ & 1.2 & 1.2 & 1.3 \\
\hline $65 \%$ & 0.9 & 1.4 & 1.3 \\
\hline $70 \%$ & 0.3 & 1.1 & 1.6 \\
\hline $75 \%$ & 0 & 0.2 & 0.5 \\
\hline $80 \%$ & 0 & 0 & 0 \\
\hline $85 \%$ & 0 & 0 & 0 \\
\hline $90 \%$ & 0 & 0 & 0 \\
\hline $95 \%$ & 0 & 0 & 0 \\
\hline $100 \%$ & 4.5 & 4.5 & 4.5 \\
\hline
\end{tabular}

Table C1: Tabulated values for inter-row shading irradiance (3-up landscape) matched to a $5 \%$ bin frequency (the bin label represents the maximum value in the bin) 


\section{Appendix D: Maxim VT8024 Residential Shade Test}

Section 5.1 includes field data and results from a Maxim Integrated inter-row shading test, where partial shading is applied and results are weighted in a manner appropriate for multi-row shade conditions. Maxim's DC-DC converters can also be applied to residential installations, which is the focus of the original shade methodology described in Section 3. To compare Maxim's technology against other distributed power electronics under controlled shade conditions, the NREL shade-test protocol from Section 3 is applied to a Maxim installation at the Sandia Regional Test Center site in Albuquerque, NM.

In this case, the Device Under Test (DUT) is the Maxim VT8024 embedded electronic module, which uses three DC-DC converters per 72-cell panel. This smart module is designed to reduce inter-row shading losses when installed in landscape configuration (rather than the portrait configuration of the VT8012 device); so the site is configured with rows in 2-up landscape (Figure D.1). Here, we investigate the same smart module's ability to reduce losses from the more arbitrary shading seen in residential conditions.

Two parallel strings of 10 panels each are used in the DUT array (with VT8024 chips embedded) having a 6,000-watt-rated system power. The Reference array (without VT8024 chips) is composed of two strings of JA Solar JA6P-300 conventional 72-cell modules, 10 modules per string, and also a 6,000-watt-rated system power.

Both the DUT array and the Reference array are connected to conventional string inverters (Power-One PVI-6000) to provide DC-to-AC conversion. String-level performance is monitored by calibrated current and voltage transducers (AcuEnergy's AcuDC string monitoring).

Details of the two systems are provided in Table D.1 below.

Table D.1. System parameters for the DUT array and the Reference array

\begin{tabular}{|c|c|c|}
\hline & Reference Array & DUT Array \\
\hline Inverter & Power-One PVI-6000-US & Power-One PVI-6000-US \\
\hline Grid Connection & \multicolumn{2}{|c|}{ 277-volt single-phase } \\
\hline Module & $\begin{array}{l}\text { JA6P-300 Conventional } \\
\text { multi-crystalline } 72 \text {-cell } \\
\qquad 300 \mathrm{~W}\end{array}$ & $\begin{array}{l}\text { 300-W 72-cell multi- } \\
\text { crystalline with Maxim } \\
\text { VT8024 (junction box) }\end{array}$ \\
\hline \# of Strings & \multicolumn{2}{|c|}{2} \\
\hline \# of Modules/String & \multicolumn{2}{|c|}{10} \\
\hline Nameplate DC Power & \multicolumn{2}{|c|}{$6 \mathrm{~kW}$} \\
\hline CEC Efficiency & $96.5 \%$ & $96.5 \% *$ \\
\hline System Location & \multicolumn{2}{|c|}{ Albuquerque, NM } \\
\hline System Orientation & \multicolumn{2}{|c|}{ 30-degree south-facing, landscape orientation } \\
\hline Testing Dates & \multicolumn{2}{|c|}{ August 16 to August 18, 2016} \\
\hline
\end{tabular}

*DUT conversion efficiency is included in the $300-\mathrm{W}$ factory flash value of the PV module 
As with the experiment described in Section 4.1, the configuration here consists of two parallel strings of modules. Partial-shading performance is monitored over 20 shading conditions, using $37 \%$ transparent shading fabric over a variety of shade extents. Given 10 modules per string with three diodes per module, there are a total of 30 diode-protected submodules per string. Therefore, the two shading configurations tested were $n: 0$ (single string) and $n: n$ (dual string) shading, where $n$ is the number of covered submodules: $1,3,6,9,12,15,18,22,26$, or 30 .

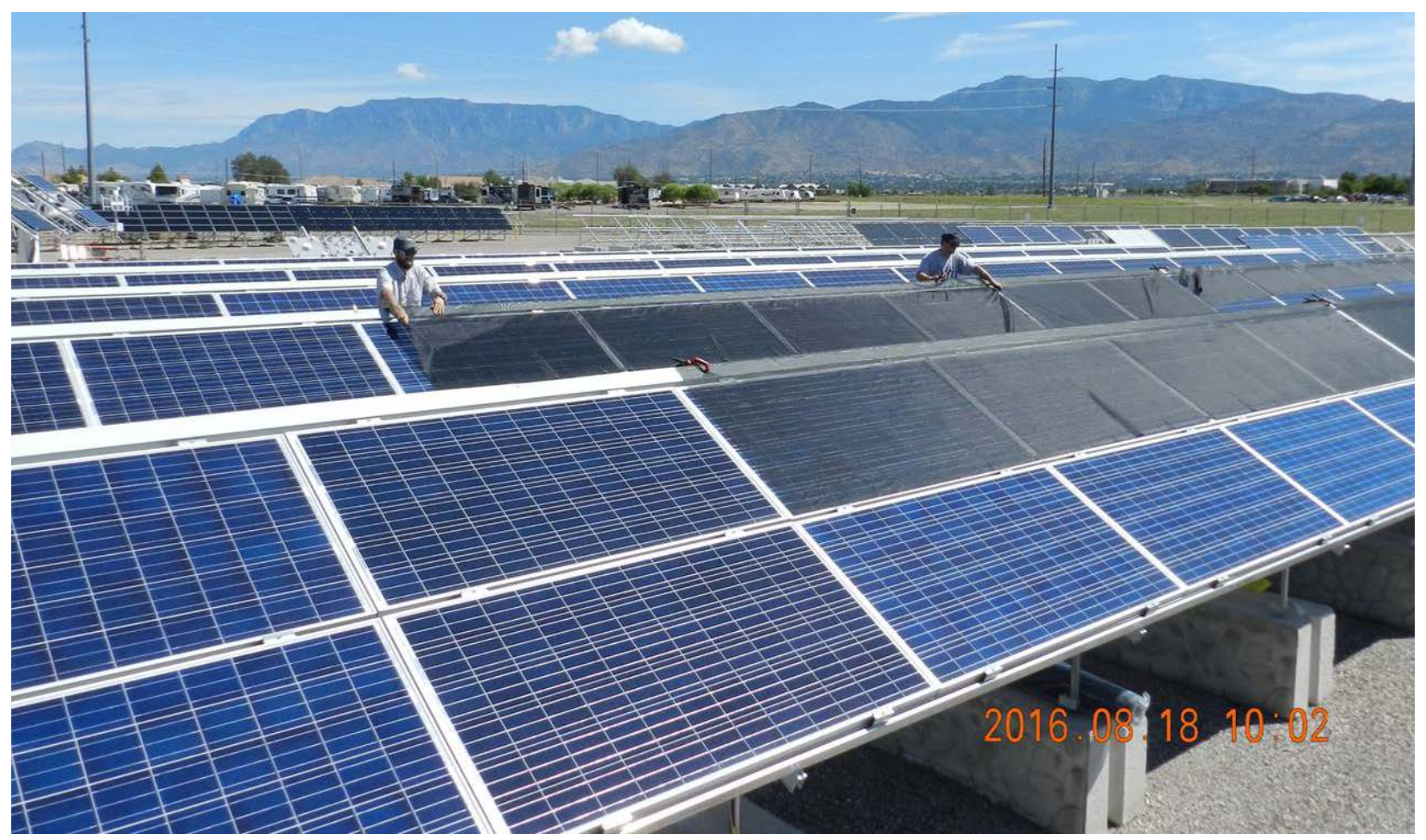

Figure D.1. Shading mesh applied to both rows of the Maxim installation.

The Normalized Performance of the two DUT systems and the Reference system are shown in Fig. D.2, calculated by Eq. (2). The shaded results are compared with unshaded data, measured within two days of the shaded experiments. By translating data to STC conditions-as well as comparing against unshaded data at the same time of day-variable conditions such as temperature, irradiance, and differences in PV module nameplate rating are removed from the comparison. 


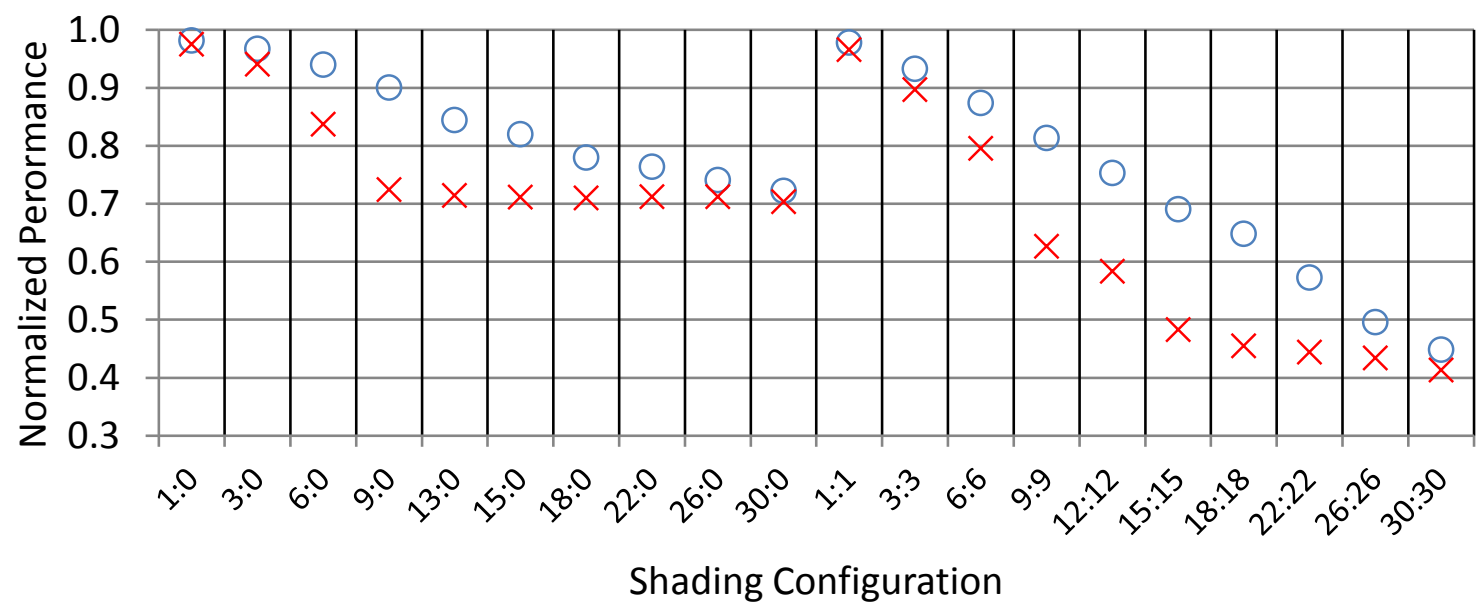

Figure D.2. Normalized Performance of the three systems under 22 partial-shading conditions.

Inspection of the Normalized Performance in Fig. D.2 indicates that the Maxim DUT array follows a linear response comparable to that in Fig. 8 from the SolarEdge and Enphase DUT arrays. Likewise, the Reference Array in this experiment follows a similar nonlinear response to that of the Reference Array in Fig. 4 and Fig. 8.

The above experimental results are analyzed according to the method described in Section 3.3. Namely, linear interpolation of data points match the $n: 0$ and $n: n$ results to the $5 \%$ shading bins of Appendix A. For $0 \%-50 \%$ system shading where both $n: 0$ and $n: n$ results contribute, the values are weighted with $n: n$ results counting for twice the value of $n: 0$ results. This weighted average is based on Fig. 9 of [1], which shows a greater proportion of uniform (n:n) shading than isolated $(n: 0)$ shading; the sensitivity of the analysis to the weighting value is very small.

Following interpolation, the Normalized Performance is used to calculate total Energy and Shade Mitigation Factor for the Maxim VT8024 system under different shading conditions, according to Eqs. (3)-(5). These results are provided in Table D.2.

Table D.2. Summary of shade study results - Maxim VT8024, Residential Shading

\begin{tabular}{|lccc|}
\hline \multicolumn{1}{|c}{ Parameter } & Light & Moderate & Heavy \\
\hline \% of System Shading [\%] & 7.6 & 19.0 & 25.5 \\
\hline Unshaded Energy $\left[\mathrm{kWh} / \mathrm{m}^{2}\right]$ & 1,813 & 1,893 & 1,784 \\
\hline Maxim Energy $\left[\mathrm{kWh} / \mathrm{m}^{2}\right]$ & 1,741 & 1,647 & 1,477 \\
\hline Reference Energy $\left[\mathrm{kWh} / \mathrm{m}^{2}\right]$ & 1,710 & 1,579 & 1,382 \\
\hline Shade Mitigation Factor $[\%]$ & 30 & 22 & 24 \\
\hline Average Shade Mitigation Factor $[\%]$ & & 25 & \\
\hline
\end{tabular}


Maxim's Shade Mitigation Factor (SMF) average of 25\% compares favorably with the previous products tested and summarized in Table 9: Enphase SMF $=23 \%$ and SolarEdge SMF $=25 \%$. Therefore, within the experimental uncertainty of the methodology, Maxim's VT8024 embedded power electronics applied at the submodule level behave on par with other module-level solutions under similar shade conditions, or even slightly improved because of the 3-per-module granularity of the VT8024 power electronics devices. The increased granularity of this solution can enable improved response under small increments of shade that do not cover an entire module, relative to a module-level approach. This particular experiment may not have been configured to fully quantify this benefit. 